\title{
Dendrodendritic and Axoaxonic Synapses in the Thalamic Reticular Nucleus of the Adult Rat
}

\author{
Didier Pinault, ${ }^{1}$ Yoland Smith, ${ }^{1,2}$ and Martin Deschênes ${ }^{1}$ \\ ${ }^{1}$ Centre de Recherche en Neurobiologie, Hôpital de l'Enfant-Jésus, Département de Physiologie, Faculté de Médecine, \\ Université Laval, Québec, Canada, G1J 1Z4, and 'Division of Neuroscience, Yerkes Regional Primate Center and \\ Department of Neurology, Emory University, Atlanta, Georgia 30322
}

Currently, it is believed that cell-cell communications occur in the thalamic reticular nucleus (RT) during thalamocortical operations, but the anatomical substrate underlying these intrinsic interactions has not been characterized fully in the rat yet. To further our knowledge on this issue, we stained juxtacellularly rat $\mathrm{RT}$ neurons with biocytin or Neurobiotin and examined their intrinsic axon collaterals and "axon-like processes" at both light and electron microscopic levels. Of 111 tracer-filled RT cells for which the axon could be followed from its origin up to the thalamus, 12 displayed short-range, poorly ramifying varicose local axon collaterals, which remained undistinguishable from parent distal dendrites, raising the question as to whether their varicosities were presynaptic terminals. Correlated light and electron microscopic observations of the proximal part of these intrinsic varicose axonal segments revealed that their varicosities and intervaricose segments were, in fact, postsynaptic structures contacted by a large number of boutons that, for the most, formed asymmetric synapses and were nonimmunoreactive for GABA. Similarly, the so-called "axon-like processes" stemming from the soma or dendrites also were identified as postsynaptic structures. Two unexpected observations were made in the course of this analysis. First, the hillock and initial segment of some RT axons were found to receive asymmetric synaptic inputs from GABA-negative terminals. Second, examination of serial ultrathin sections of dendritic bundles cut in their longitudinal plane revealed the existence of several short symmetric dendrodendritic synapses and numerous puncta adhaerentia between component dendrites. In conclusion, dendrodendritic junctions might be a prominent anatomical substrate underlying interneuronal communications in the RT of the adult rat. Furthermore, excitatory axoaxonic synapses on the axon hillock, initial segment, and local axon collaterals might represent a powerful synaptic drive for synchronizing the firing of RT neurons. Future studies are essential to verify whether excitatory axoaxonic synapses with the axon hillock are a general feature in the RT.

Key words: axon hillock; axon initial segment; cell-cell communication; correlated light and electron microscopy; juxtacellular labeling; thalamic network
The thalamic reticular nucleus (RT) is a diencephalic shell-shaped structure, the constituents of which are GABAergic neurons (Houser et al., 1980) with dendritic bundles embedded in a dense neuropil of presynaptic boutons that mostly arise from corticothalamic and thalamocortical axons (Scheibel and Scheibel, 1966, 1972). The RT is thus the inhibitory interface between thalamocortical and corticothalamic systems that fashions and synchronizes the thalamocortical action potential discharges by playing back exclusively on thalamic neurons (Steriade et al., 1984; Thomson, 1988).

For a long time it has been advocated that RT neurons synaptically communicate between each other during thalamocortical operations, especially during thalamic oscillations (Steriade et al., 1990). However, the morphofunctional substrate that underlies such intranuclear cell-cell communications always has remained elusive. Scheibel and Scheibel (1972) were the first to postulate,

Received July 29, 1996; revised Jan. 21, 1997; accepted Jan. 28, 1997.

This study was supported by grants from the Medical Research Council of Canada and the Fonds de la Recherche en Santé du Québec. We thank Jean-François Paré for his expert technical assistance, R. W. Guillery for constructive comments on this manuscript, and A. Parent for his critical reading.

Correspondence should be addressed to Dr. Didier Pinault, Institut National de la Santé et de la Rechurche Médicale U. 398, Faculte de Médecine, 11, rue Humann, 67085 Strasbourg Cedex, France.

Drs. Pinault and Deschêne's present address: Le Centre de Recherche, Université Laval Robert-Giffard, 2601 De La Canardière, Beauport, Québec, Canada, G1J 2G3.

Copyright (C) 1997 Society for Neuroscience 0270-6474/97/173215-19\$05.00/0 on the basis of light microscopic analysis of Golgi-impregnated neurons in adult animals, that dendrodendritic interactions may take place in the RT. In line with the Scheibels' hypothesis, electron microscopic analyses revealed that RT cell dendrites form a local network of symmetric dendrodendritic synapses in adult cats (Ide, 1982; Montero and Singer, 1984; Deschênes et al., 1985; Yen et al., 1985). In contrast, few if any dendrodendritic synapses have been seen in the RT of rats (Ohara and Lieberman, 1985) and monkeys (Ohara, 1988; Williamson et al., 1994), suggesting that in these species RT neurons might interact with each other by way of another mechanism. In this regard, light microscopic examination of tracer-filled RT neurons suggested that they possess intrinsic beaded axon collaterals and dendrites ending in fine varicose processes resembling synaptic terminals ("axon-like processes") in rats (Spreafico et al., 1988) and cats (Yen et al., 1985; Mulle et al., 1986; Uhlrich et al., 1991; Lübke, 1993; Liu et al., 1995). It recently has been reported that in young rats $\sim 65 \%$ of RT neurons give rise to intrinsic axon collaterals (Cox et al., 1996), conjuring up Scheibel and Scheibel's observations (1966) of a dense network of intrinsic axon collaterals in Golgi-stained RT neuropil of young animals. On the other hand, when examining the axonal arborization of a large number of biocytin-filled RT neurons in the adult rat, Pinault et al. (1995a,b) noticed that the axons of these neurons left the nucleus without giving off local collaterals. 
It is noteworthy that in none of the previous studies suggesting the existence of intrinsic axon collaterals in the RT has the ultrastructure and synaptic organization of the thin axonal branches, which were identified as local collaterals, been depicted. Similarly, the ultrastructure of the so-called "axon-like processes" has never been characterized, and the assumption that these elements are presynaptic is based on light microscopic observations. Therefore, to further our knowledge on the intrinsic mechanisms underlying cell-cell communication in the RT, we examined the structural features and synaptic organization of identified intrinsic axon collaterals and axon-like processes of juxtacellularly stained rat RT neurons in the light and electron microscopes.

Preliminary results of this study have been presented in abstract form (Pinault et al., 1996).

\section{MATERIALS AND METHODS}

Sixty-eight Sprague Dawley male rats weighing 280-350 gm were used in this study. All surgical and animal care procedures adhered to the Handbook for the Use of Animals in Neuroscience Research (1991) and to the Guide to the Care and Use of Experimental Animals in Canada (1993).

\section{Histochemical markers}

The biotin-lysine complex (biocytin; Sigma, St. Louis, MO) or $N-(2$ aminoethyl) biotinamide hydrochloride (Neurobiotin; Vector Laboratories, Burlingame, CA) was dissolved at $1.5 \%$ in $0.5 \mathrm{M}$ of $\mathrm{CH}_{3} \mathrm{COOK}$ or $\mathrm{NaCl}$ and micropore-filtered.

\section{Anesthesia and surgery}

Animals were deeply anesthetized with urethane (ethyl carbamate, Sigma; initial dose: $1.4 \mathrm{gm} / \mathrm{kg}$, i.p.) and immobilized in a stereotaxic frame throughout the acute experiment. They were self-breathing, and the depth of anesthesia was ascertained by the lack of withdrawal reflex to hindlimb pinching or of a blink reflex to gentle stimulation of the cornea; additional doses of anesthetic were given, when necessary. Rectal temperature was kept at $37^{\circ} \mathrm{C}$ with a heating pad controlled by a feedback circuit. Conventional craniotomies were made over the left and right $\mathrm{RT}$.

\section{Microelectrodes, stereotaxy, and electrophysiology}

Microelectrodes were prepared from $1.5 \mathrm{~mm}$ glass capillaries containing a microfilament (A-M Systems) on a Narishige PE-2 vertical puller. They were filled with the solution containing the marker molecules, and their tips were broken to an external diameter of $\sim 1.5 \mu \mathrm{m}$. Connected to an intracellular recording amplifier (IR-283; Neuro Data), the micropipettes (DC resistance, $\sim 40 \mathrm{~m} \Omega$ ) were proceeded down with a stepping microdriver (nanostepper, List) to reach single RT neurons via the use of the stereotaxic atlas of Paxinos and Watson (1986).

RT neurons were identified on the basis of their burst or clock-like monotonous action potential discharges (Pinault and Deschênes, 1992a). Some of them were characterized further either by their typical shortlatency burst response after electrical stimulation of the internal capsule or their firing evoked by stimulation of the receptive field. The action potential of RT neurons was characteristically shorter in duration than that of thalamic projection neurons. The burst discharge of RT cells was also easily distinguishable from that of thalamic relay neurons because it was usually longer, a unique characteristic known to be attributable to a longer-in-duration low-threshold calcium-dependent spike than that occurring in the latter cells (Huguenard and Prince, 1992).

Electrophysiologically identified RT cells were labeled individually after juxtacellular iontophoresis of biocytin or Neurobiotin. Using the bridge circuitry of the recording amplifier (IR-283, Neuro Data Instrument), we applied the tracer with a $50 \%$ duty cycle of $200 \mathrm{msec}$ anodal current pulses of 1-8 nA during at least 5 min under continuous electrophysiological control (see Fig. $3 A 1-A 3)$. Details of the filling protocol have been described elsewhere (Pinault, 1994, 1996).

\section{Histological procedures}

After a survival period of 2-6 hr, the animals were given an overdose of urethane and then transcardially perfused with physiological saline $(0.9 \%$ of $\mathrm{NaCl}, 200 \mathrm{ml}$ ), followed by $750 \mathrm{ml}$ of a fixative containing $4 \%$ paraformaldehyde and $0.5 \%$ glutaraldehyde in $0.1 \mathrm{M}$ phosphate buffer
(PB; $\mathrm{pH}$ 7.4). Frontal or horizontal brain sections were cut at $60-100 \mu \mathrm{m}$ with a vibrating microtome (Campden Instruments, Berlin, Germany) and serially collected in PB. Then they were processed for the localization of tracer-filled neurons at the light microscopic level only (63 rats, 118 neurons) or for correlated light and electron microscopic studies (5 rats, 37 neurons).

Light microscopy. Sections were washed thoroughly in PB before being incubated for at least $4 \mathrm{hr}$ at room temperature with a 1:100 avidinbiotin-peroxidase complex (ABC; Vector Laboratories) solution containing $0.3 \%$ Triton $\mathrm{X}-100$ and $1 \%$ bovine serum albumin in $\mathrm{PB}(0.1 \mathrm{M}, \mathrm{pH}$ 7.4). Then the tracer was revealed with $3,3^{\prime}$ diaminobenzidine tetrahydrochloride (DAB) intensified with nickel (Adams, 1981). The sections were mounted on chrome alum gelatin-coated slides, and coverslips were applied with Permount. To demarcate nuclear boundaries, we removed the coverslips of some sections and counterstained the tissue with cresyl violet.

Correlated light and electron microscopy. Before being processed to reveal the injected marker, the sections prepared for electron microscopy were placed in a cryoprotectant solution $(\mathrm{PB}, 0.05 \mathrm{M}, \mathrm{pH} 7.4$, containing $25 \%$ sucrose and $10 \%$ glycerol) for 20-30 min. After having sunk, they were frozen at $-80^{\circ} \mathrm{C}$ for $20 \mathrm{~min}$. They then were thawed, washed many times in PBS $(0.01 \mathrm{M}, \mathrm{pH} 7.4)$, and processed in the same way as the sections prepared for light microscopy, except that Triton $\mathrm{X}-100$ was omitted and the incubation in the $\mathrm{ABC}$ solution lasted for 48 $\mathrm{hr}$ at $4^{\circ} \mathrm{C}$. After having been processed, the sections were washed in $\mathrm{PB}$ $(0.1 \mathrm{M}, \mathrm{pH} 7.4)$ before being post-fixed in osmium tetroxide $(1 \%$ solution in PB) for $20 \mathrm{~min}$. They then were dehydrated in a graded series of alcohol and propylene oxide. Uranyl acetate $(1 \%)$ was added to the $70 \%$ ethanol $(30 \mathrm{~min})$ to improve the contrast in the electron microscope. Then the sections were embedded in resin (Durcupan, ACM, Fluka, Neu-Ulm, Germany) on microscope slides and put in the oven for $48 \mathrm{hr}$ at $60^{\circ} \mathrm{C}$. After examination in the light microscope, regions of interest were cut out from the slides and glued on the top of resin blocks with cyanoacrylate glue. Serial ultrathin sections then were cut on a Reichert-Jung Ultracut E ultramicrotome and collected on Pioloform-coated single-slot copper or gold grids. The sections collected on copper grids were stained with lead citrate (Reynolds, 1963) and examined with a Phillips EM 300 electron microscope. The sections collected on gold grids were processed for postembedding immunocytochemistry for GABA.

Postembedding immunocytochemistry. The postembedding immunogold procedure was performed with an antiserum raised in rabbit against GABA (Hodgson et al., 1985) of which the production, characterization, and specificity have been described in detail elsewhere (Hodgson et al., 1985; Somogyi and Hodgson, 1985; Somogyi et al., $1985)$. The protocol for immunostaining was that introduced by Somogyi and Hodgson (1985) with modifications (Phend et al., 1992). Briefly, a series of adjacent ultrathin sections were preincubated for $10 \mathrm{~min}$ in Tris-buffered saline (TBS; $0.05 \mathrm{M}, \mathrm{pH} 7.6$ ) containing $0.01 \%$ Triton $\mathrm{X}-100$. This was followed by an overnight incubation at room temperature with the GABA antiserum diluted 1:5000 in TBS with $0.01 \%$ Triton $X-100$. Then the sections were washed three times $(2 \times$ for 10 $\min ; 1 \times$ for $30 \mathrm{~min}$ ) in TBS with $0.01 \%$ Triton $\mathrm{X}-100$, followed by TBS $(0.05 \mathrm{M}, \mathrm{pH} 8.2)$ for $10 \mathrm{~min}$. They then were incubated with the gold-conjugated goat anti-rabbit IgG (BioCell, Cardiff, UK; 1:25 in TBS $0.05 \mathrm{M}, \mathrm{pH} \mathrm{8.2)} \mathrm{for} 90 \mathrm{~min}$ at room temperature, washed in distilled water, and stained with uranyl acetate (1\% in distilled water) for $90 \mathrm{~min}$. Finally, after having been washed in distilled water and stained with lead citrate (Reynolds, 1963), they were examined with a Phillips EM 300 electron microscope.

An element was considered immunoreactive for GABA if the density of gold particles associated with it was at least five times higher than the density of gold particles associated with terminals that formed asymmetric synapses in the same section. In addition, the density of labeling had to be the same in at least two serial sections.

The specificity of labeling was tested by incubation with solutions in which the primary antisera were replaced with nonimmune rabbit serum. After such incubation the tissue was devoid of gold particles, indicating that the GABA immunostaining described in the present study is specific. Another series of control grids were incubated with GABA antiserum that had undergone liquid phase preadsorption with structurally related amino acids conjugated to ethanolamine with glutaraldehyde (Dale et al., 1986). The antiserum was preadsorbed with taurine, GABA, glutamate, and glutamine conjugates. After such incubations the tissue was devoid almost completely of gold particles in the cases in which the GABA 


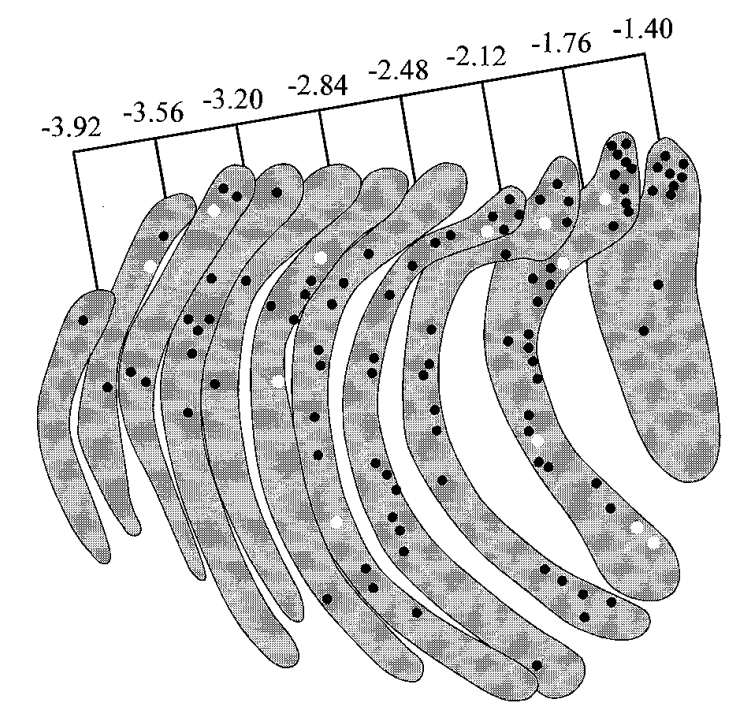

Figure 1. Schematic drawing through the rostrocaudal extent of the RT to illustrate the location of the 111 biocytin- or Neurobiotin-filled RT neurons with a well identified origin of the axon. The white dots indicate the 12 neurons, the axons of which gave rise to intrinsic collaterals. The negative numbers correspond to the anteroposterior distances (in $\mathrm{mm}$ ) between the bregma and the frontal RT sections (each $0.2 \mathrm{~mm}$ apart). $A$, Anterior; $D$, dorsal; $L$, lateral. antiserum was preadsorbed with the GABA-glutaraldehyde conjugate. In contrast, preadsorption of the antiserum with other amino acid conjugates had no effect on the intensity of staining.

\section{Reconstruction and analysis}

Light microscopic analysis. The tracer-filled RT neurons $(n=118)$ were examined first with a light microscope at low $(10-60 \times)$ magnification to select those $(n=88)$ for which the axon was clearly visible from its origin to its entry into the thalamus. We reconstructed the axonal course via serial sections for selected cells at a higher magnification with a $100 \times$ oil-immersion objective, a drawing tube, and an image-combining computer microscope (Neurolucida, Microbrightfield, Colchester, VT).

Correlated light and electron microscopic analysis. The light microscopic analysis of the tracer-filled RT neurons prepared for electron microscopy $(n=37)$ was similar to that described above. The axons of $23 \mathrm{RT}$ neurons could be followed from their origins to the thalamus. Two of the axons, which possessed intrinsic axon collaterals, were reconstructed at $40 \times$ and photographed before being cut as ultrathin sections for analysis in the electron microscope.

Electron microscopic analysis of unlabeled elements. The axon hillock and initial segment, as well as the primary dendrites, of four unlabeled RT cells were examined via serial ultrathin horizontal sections in the electron microscope.

\section{RESULTS}

\section{General observations}

The results presented in this study were obtained from 155 biocytinor Neurobiotin-filled neurons located in different sectors of the RT (Fig. 1). Although most $(n=127)$ of them had a completely stained axon arborizing into the ipsilateral thalamus (see Fig. 3), only those $(n=115)$ having their axon hillock and initial segment clearly visible were considered in the present study. Regarding the axonal origin as the point or the node from which arose a process that was thinner and smoother than an ordinary dendrite, we categorized the RT neurons into three groups: those with an axon emerging from the perikaryon ( $n=54$; group 1 ) (Fig. $2 A 1, B)$, those with an axon originating from a proximal dendrite at an average distance of $20.6 \pm$ $17.2 \mu \mathrm{m}$ from the soma ( $n=57$; group 2$)$ (Figs. $2 A 2, B, 3)$, and those for which the axon appeared as the continuation of a dendrite $(n=$ 4; group 3) (Figs. 2A3, 4). The criteria used for the identification of the axon origin in the first two groups were confirmed at the electron microscopic level (see below). Although nearly all $(n=108)$ of the selected RT cells had a single principal axon, three neurons were found with two axons coursing toward the same target: one emerging from the soma and the other from a proximal dendrite (data not shown). In some cases the axonal labeling was faint near its onset, but axonal branch points and nodes of Ranvier could be detected easily (Fig. 3b). Although the axonal trunk of most RT neurons divided just before reaching its thalamic target (see Pinault et al., 1995a,b), in many cases the axonal division started in the RT (Fig. 3). The corresponding axonal branches first coursed with different trajectories, but once in the thalamus, they switched their direction toward the same target. In other instances, especially when the target was adjacent to the RT, the axon divided several times before leaving the nucleus (data not shown).

In four cases the origin of the axon could not be ascertained because it appears as the continuation of a dendrite (Fig. 4). It is worth noting the striking resemblance between dendritic and axonal processes in these neurons. Occasionally, short drumsticklike appendages similar to those commonly seen on dendrites emerged from these beaded axonal segments. The neuron shown in Figure 4 was quite impressive, because it had two thick axons that originated from the same distal dendrite-like profile (Fig. $4 C$ ). Both axonal processes, one of them being thicker than the other, were indistinguishable from the varicose dendrites and continued to display swellings as they traveled in the thalamus toward their respective targets (Fig. 4Aa,b). In that particular case, one branch arborized into the lateral posterior nucleus, whereas the other gave rise to a few terminal boutons into the laterodorsal nucleus.

\section{RT cells with intrinsic axon collaterals}

\section{Light microscopic observations}

Of the 111 RT cells with a clearly distinguishable axon, 12 neurons gave rise to one $(n=8)$, two $(n=3)$, or four $(n=1)$ intrinsic thin and beaded branch(es) that originated at a distance of 3-116 $\mu \mathrm{m}$ from the main onset of the axon. These neurons were located in different sectors of the RT (Fig. 1, white dots) and had large fusiform, polygonal, or round perikarya bearing smooth, varicose, or sparsely thorny den- 

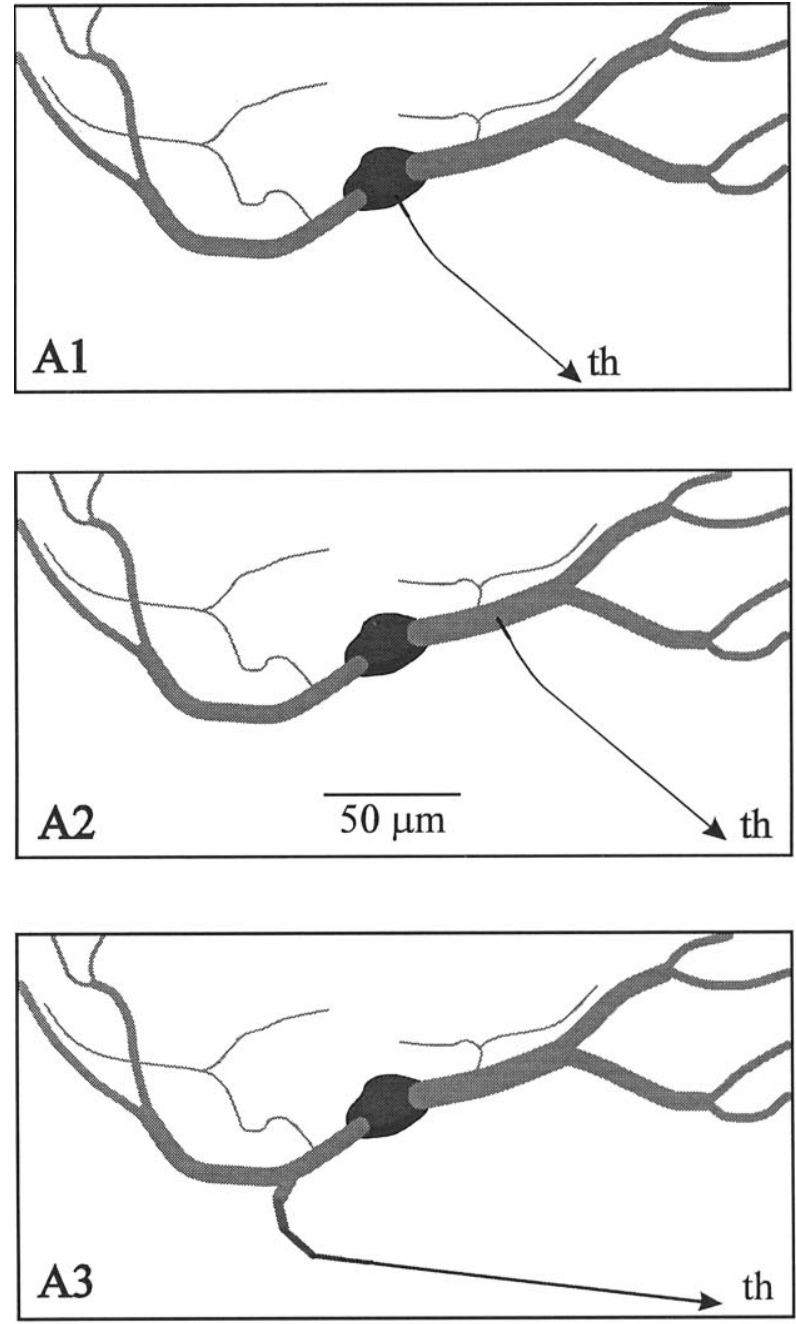

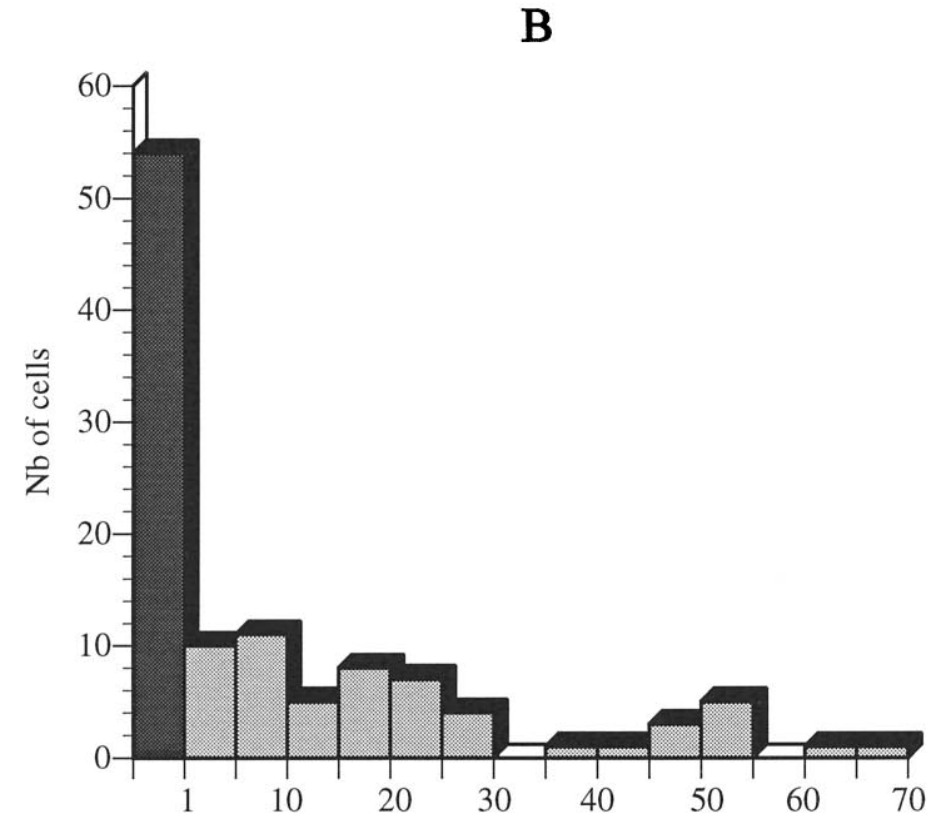

Distance from soma $(\mu \mathrm{m})$

Figure 2. Schematic drawings to illustrate the axon of RT neurons that arose either from the perikaryon $(A 1)$ or dendritic shafts $(A 2, A 3)$. In general, the initial segment of the axon was readily identifiable in the light microscope, except for those being the continuation of a dendrite $(A 3)$. $B$, Shown is the distribution of the distances separating the cell body from the axon origin for the 111 RT neurons examined. Dark bar, Neurons with axons arising from the soma. Gray bars, Neurons with axons emerging from a dendrite. Scale bar in $A 2$ is valid for $A 1$ and $A 3$. th, Thalamus.

drites. Typical examples of such neurons with intrinsic collaterals are shown in Figures 5 and 6. The local ramifications had a maximal length of $\sim 150-200 \mu \mathrm{m}$ and strikingly resembled distal dendrites. In the case shown in Figure 6 , two thin identical profiles arose from the same dendrite (Fig. 6A,a). During their intranuclear course, they both mimicked distal dendrites, elaborating enlargements or varicosities alongside parent dendrites with no apparent contact (Fig. 6B,b). Whereas one of these processes displayed beaded ramifications and terminal-like varicosities, as did dendrites, the other entered in the thalamus and generated a dense axonal arbor in the ventroposterior nucleus. It is worth noting that none of the intrinsic axon collaterals identified in the present study generated terminal plexuses with structural features of intrathalamic RT terminal fields (Fig. 3a). This observation, combined with the striking resemblance between intra-RT axon collaterals and distal dendrites (Figs. 5-6), raises the question as to whether the intrinsic axon collaterals were pre- or postsynaptic elements. Correlated light and electron microscopic analysis of local axonal branches were performed to clarify this issue (Figs. 7-9).

\section{Correlated light and electron microscopic observations}

In the following account, the nomenclature of Ohara and Lieberman (1985) is used to categorize the different types of axon terminals in the RT. Accordingly, the RT contains three major types of terminals. The D-type terminals have closely packed spherical vesicles, contain few mitochondria, and form asymmetric synapses. The L-type terminals are paler, slightly larger, contain more mitochondria, have less densely packed synaptic vesicles, and also form asymmetric synapses. Finally, the F-type terminals contain loosely distributed pleomorphic vesicles, as well as numerous mitochondria, and form symmetric synapses. The ultrastructural features and synaptic organization of structures identified as axon collaterals of tracer-filled RT neurons were examined in the electron microscope.

As mentioned above, $\sim 11 \%$ of the tracer-filled RT neurons gave rise to intrinsic axon collaterals at the light microscopic level. Two of these neurons were found in sections prepared for electron microscopy. The observations made on one of them are illustrated in Figures 7-10. This neuron was located in the dorsolateral part of the caudal sector of the RT. Its perikaryon (25 $\mu \mathrm{m}$ in diameter) had a polygonal shape and gave rise to two primary dendrites arborizing profusely over long distances in the rostrocaudal plane (Fig. 7). Its axon followed a straight course toward the caudal part of the RT, entered the thalamus, and gave rise to a rich plexus of terminals in the lateral geniculate nucleus. At less than $10 \mu \mathrm{m}$ from the perikaryon, two intrinsic branches detached from the initial part of the axon. One of these collaterals traveled for $\sim 200 \mu \mathrm{m}$ toward the rostral part of the RT, whereas the other was shorter $(100 \mu \mathrm{m})$ 
A1

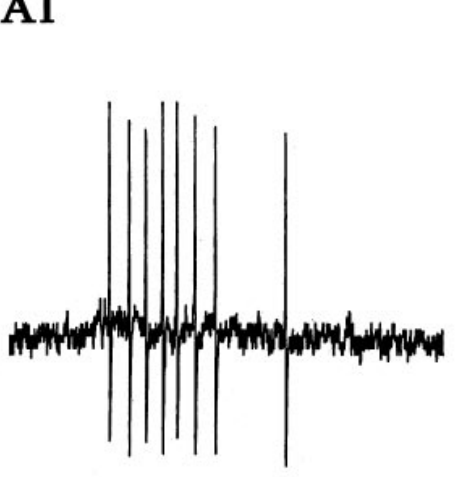

A2

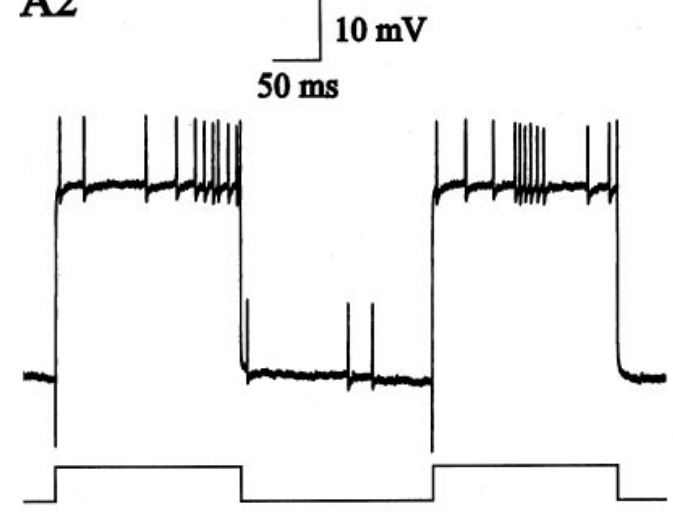

A3

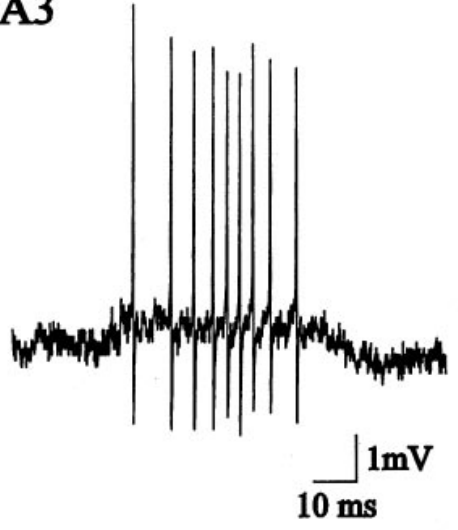

B

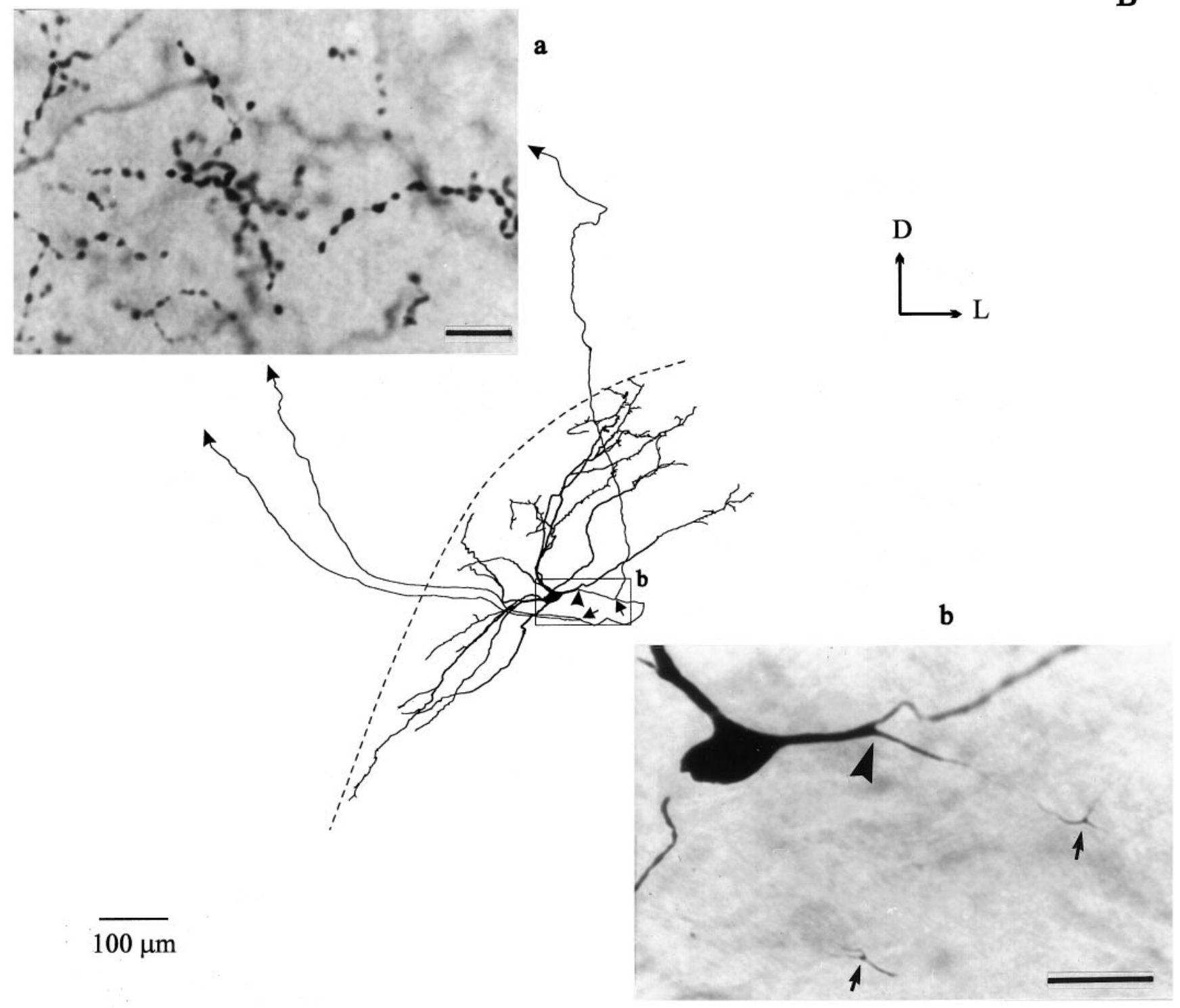

Figure 3. Typical RT neuron juxtacellularly filled with biocytin. A1, Extracellular DC recording of a typical spontaneous burst of a RT cell before tracer application. A2, Simultaneous juxtacellular DC recording (DC shift of $-6 \mathrm{mV}$ ) and juxtacellular iontophoresis with anodal current pulses (200 msec on $/ 200 \mathrm{msec}$ off; lower trace, current monitor) of $2.5 \mathrm{nA}$. $A 3$, Extracellular DC recording of a spontaneous burst a few minutes after tracer application. $B$, Caudal view of the partial three-dimensional reconstruction of the tracer-filled neuron, which survived $3 \mathrm{hr}$, to show that its axon originated from a dendrite (arrowhead) and gave off three branches converging to the same thalamic target. The framed area is shown at higher magnification in the corresponding photomicrograph $(b)$. The arrowhead indicates the axon onset; the arrows point to sites of axonal ramification. The dashed line represents the limit between the RT and the thalamus. $a$, Shown is part of the axon terminal field in the thalamus. Scale bars: $a, 10 \mu \mathrm{m} ; b, 25 \mu \mathrm{m}$. $D$, Dorsal; $L$, lateral. 

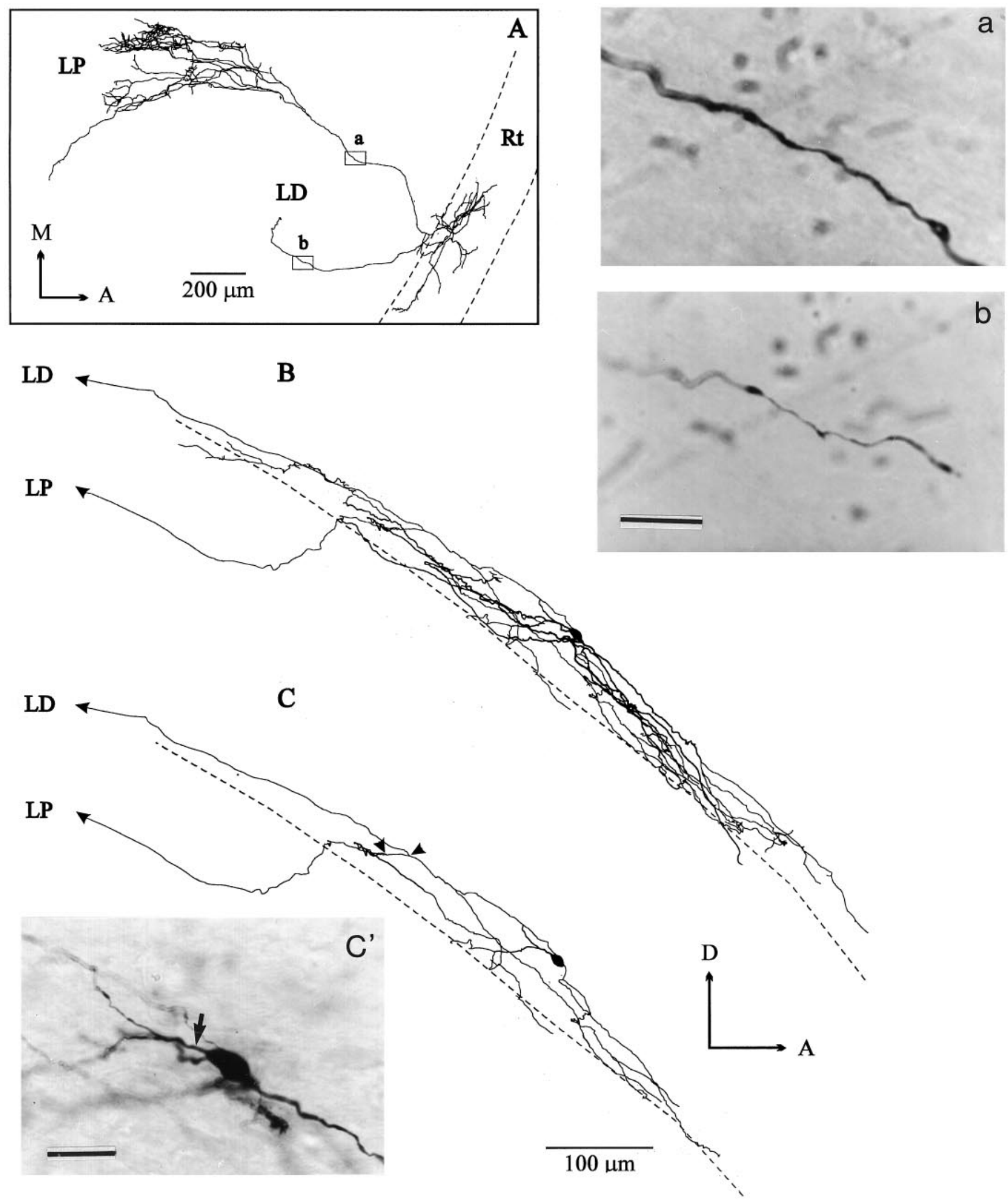

Figure 4. A tracer-filled RT neuron with two axons, which were the continuation of a dendrite. $A$, Dorsal view of its somatodendritic complex and axonal projections. The framed areas $(a, b)$ are shown at higher magnification in the corresponding photomicrographs. This neuron had two thick axons, one giving rise to an axonal arbor into the lateral posterior thalamic nucleus $(L P)$ and the other terminating in the lateral dorsal thalamic nucleus $(L D)$. These two axons, one of which $(a)$ was thicker than the other $(b)$, still had swellings when traveling in the thalamus $(a, b)$. $B$, Lateral view of the somatodendritic complex and of the initial course of the two axons, both being the continuation of a common distal dendrite. $C$, Shown is the perikaryon and the axons-bearing dendrite, separately. The arrowheads indicate the presumed onset of the two axons. The arrow in $C^{\prime}$ points to the dendrite bearing the two axons. Scale bars: $b, 10 \mu \mathrm{m}$ (also valid for $a$ ); $C^{\prime}, 20 \mu \mathrm{m}$. $A$, Anterior; $D$, dorsal; $M$, medial. 
A

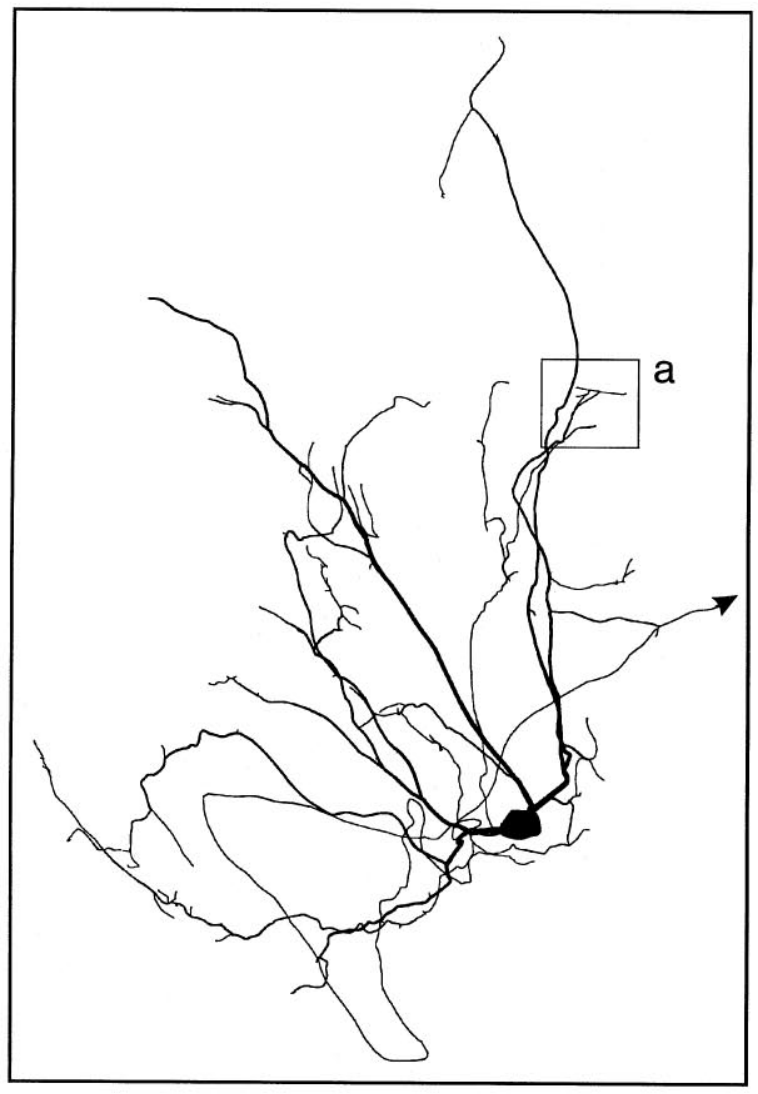

B

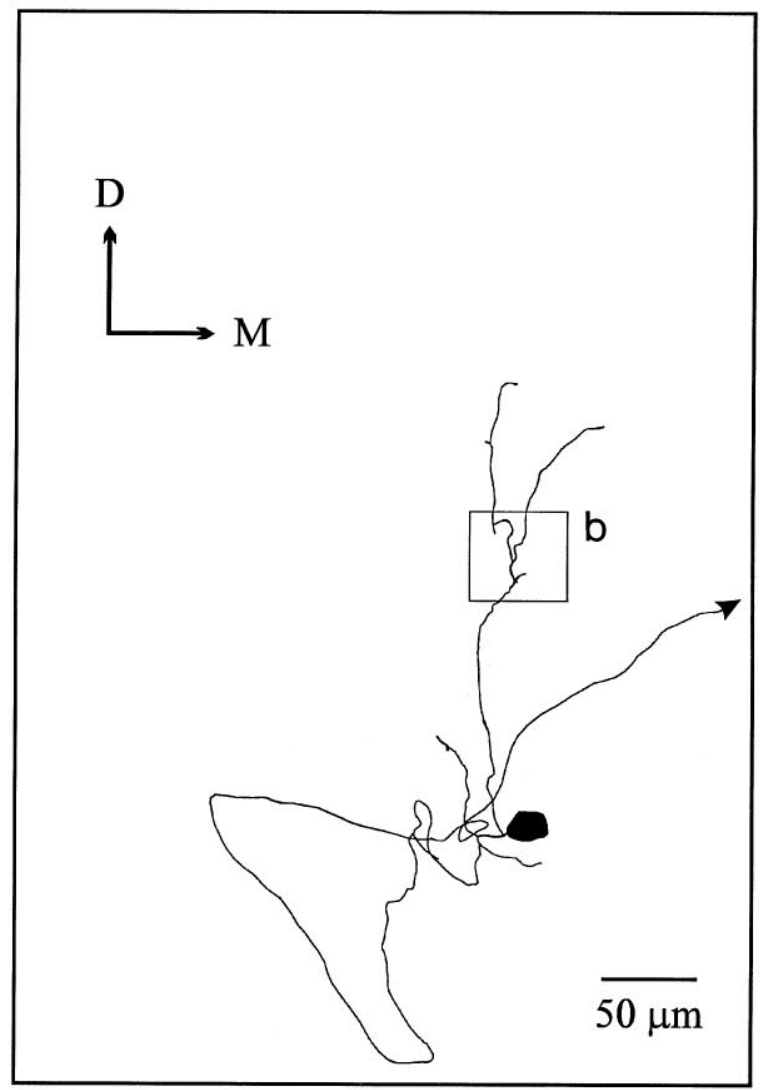

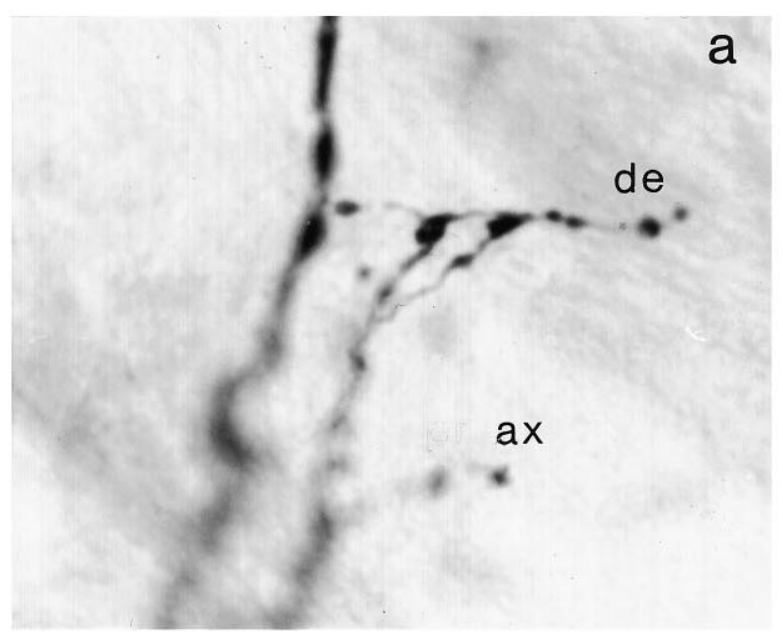

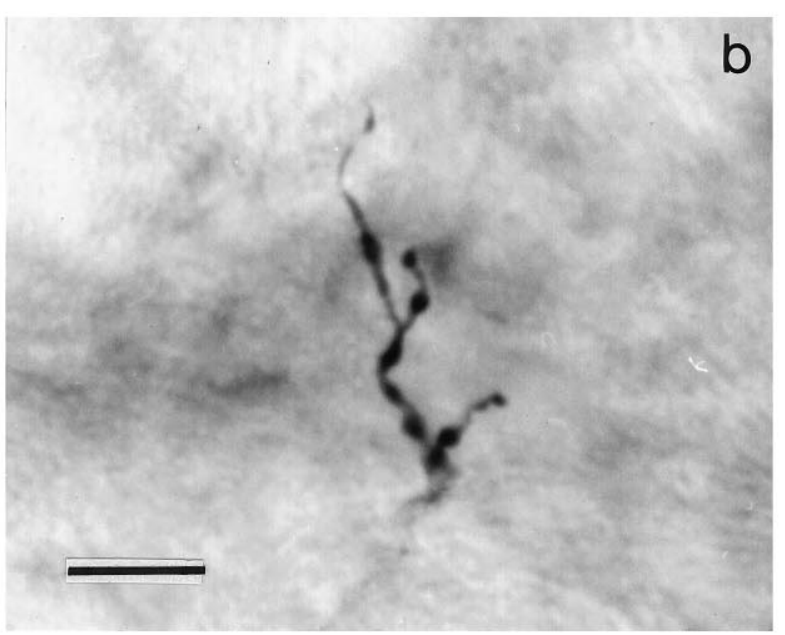

Figure 5. Juxtacellularly filled RT neuron with intrinsic beaded axon collaterals. $A$, Caudal view of its somatodendritic complex and the intranuclear portion of its axon. The framed area $(a)$, which contains a part of the axon collateral $(a x)$ and distal dendrites $(d e)$, is shown at higher magnification in the corresponding photomicrograph. $B$ illustrates only the intranuclear portion of the RT axon that started from the soma and gave rise to four ramifying varicose fibers. The framed area $(b)$ is shown at higher magnification in the corresponding photomicrograph. Scale bar in $B$ is also valid for $A$; scale bar in $b, 10 \mu \mathrm{m}$ (also valid for $a$ ). $D$, Dorsal; $M$, medial.

and oriented laterally. Both collaterals were relatively straight, with occasional varicosities (Fig. $8 A$ ).

Ultrastructural features and synaptic connections of one of these local axonal branches, which emerged from the initial axonal segment, are shown in Figure 8. Evidence that this axon collateral gave rise to presynaptic terminals could not be found in the electron microscope. On the other hand, the part of the process (10-12 $\mu \mathrm{m}$ long) that was examined in serial sections received dense asymmetric synaptic inputs from 10 GABAnegative boutons that all resembled L-type terminals (Fig. $8 C, D, F)$. The innervation was particularly dense at the level of the varicosity indicated by an arrow in Figure $8 A$. This vari- 


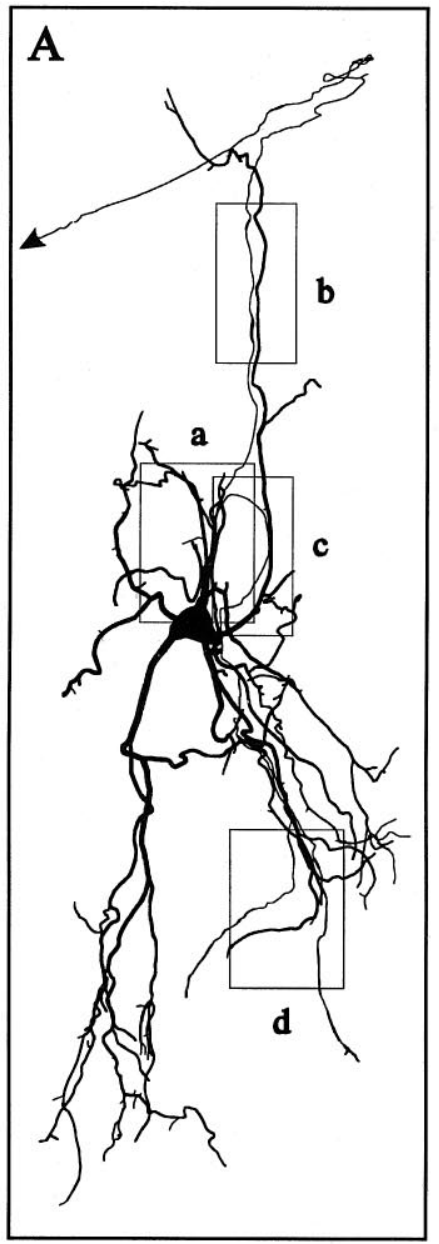

a

b

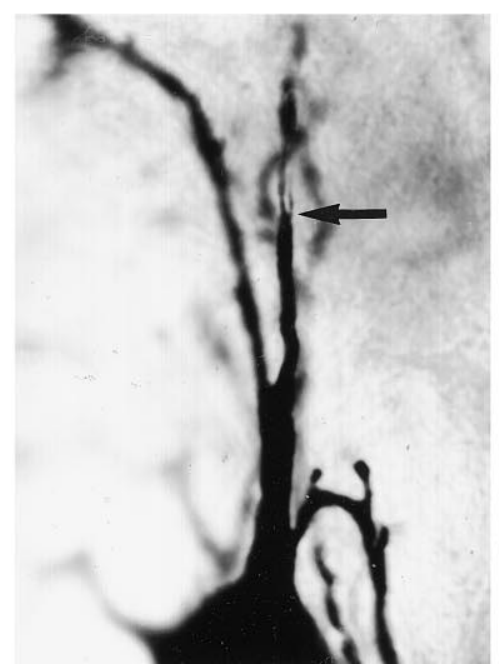

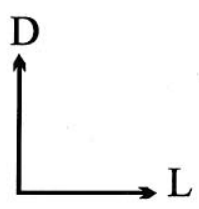

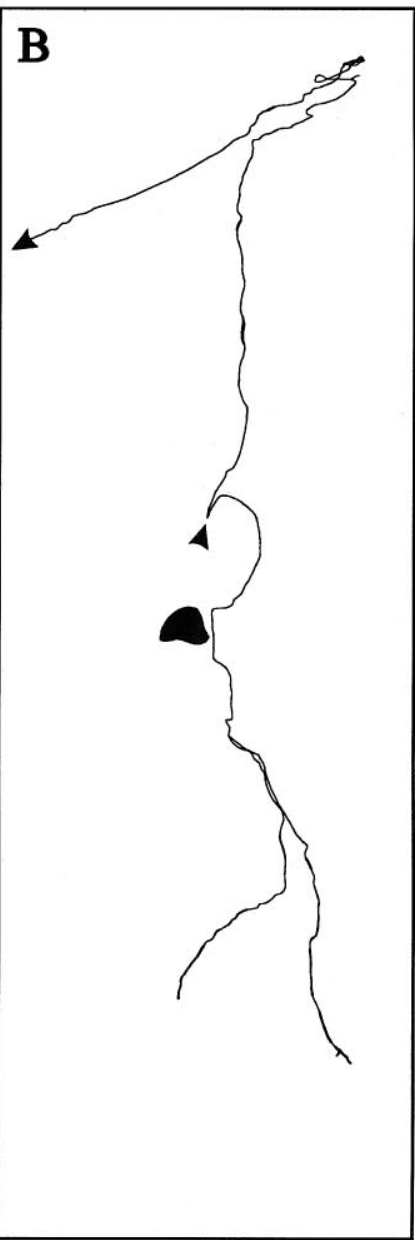

c

d

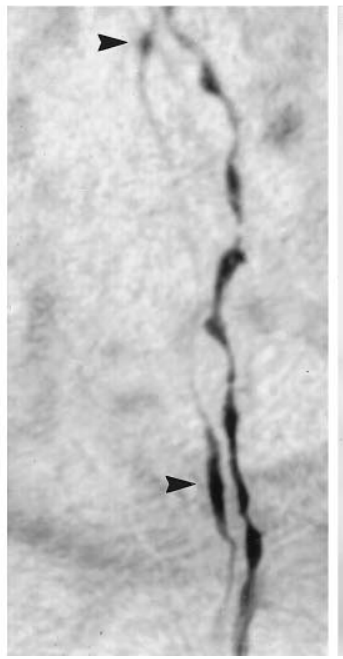

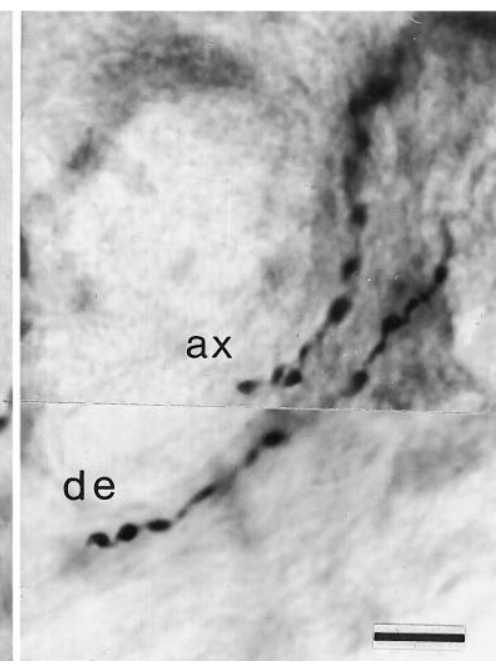

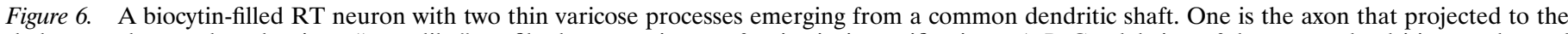

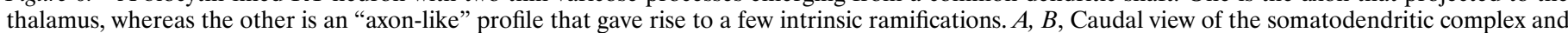

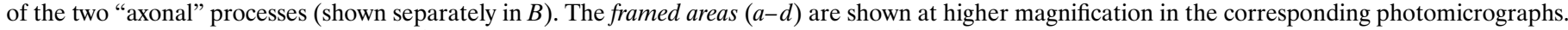

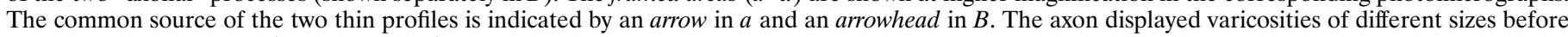

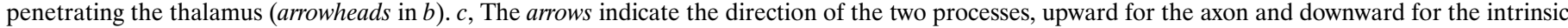

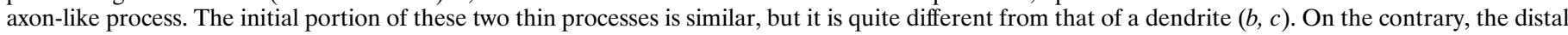

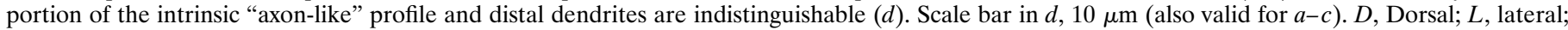
$a x$, axon; de, dendrite. 

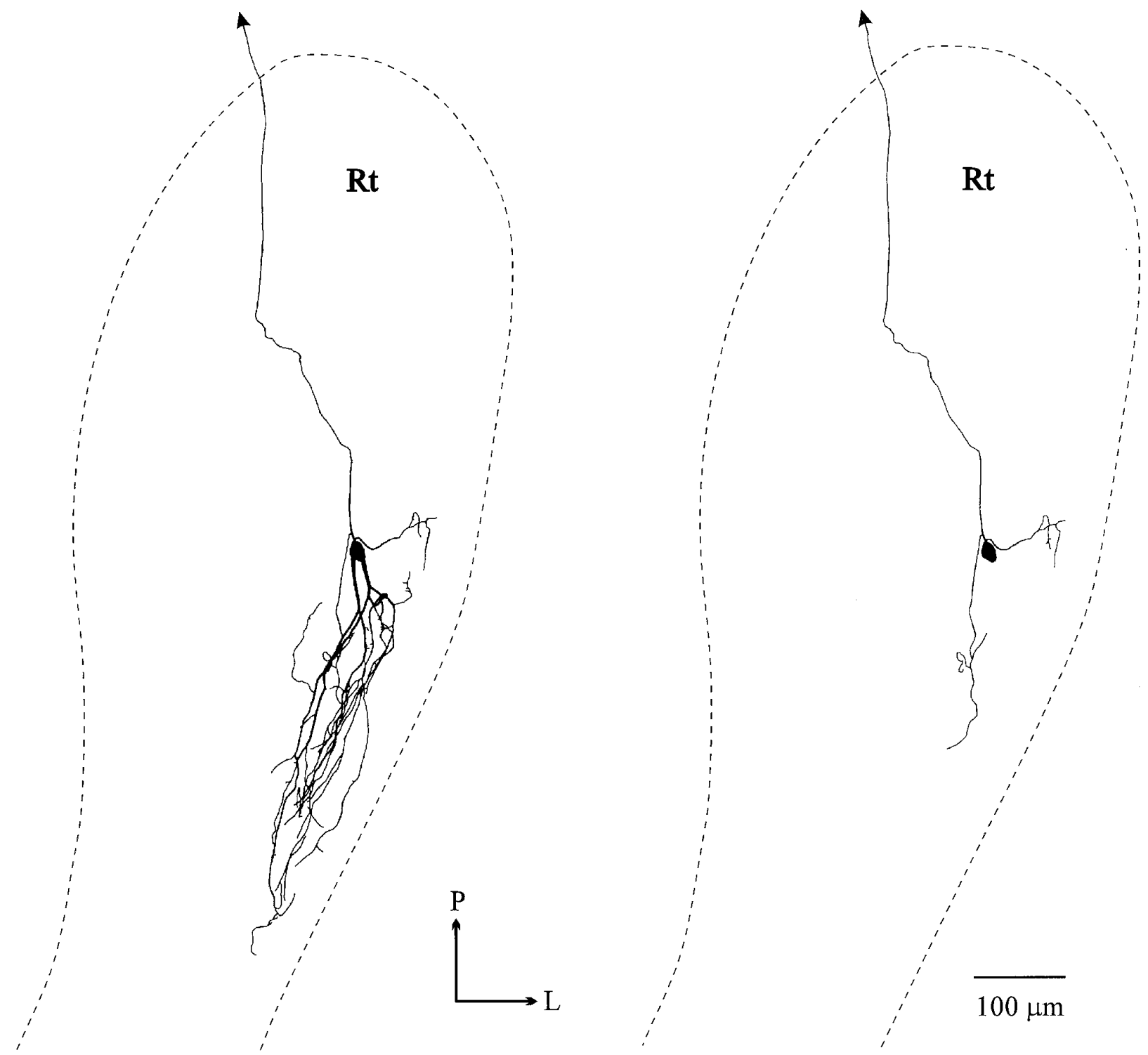

Figure 7. Dorsal view of a partial three-dimensional reconstruction of a RT neuron filled by juxtacellular application of biocytin. The dashed lines indicate the limit of the RT. The drawing on the right shows only the main axon (process with the arrowhead) from which are detached two intrinsic collaterals. Parts of the axon and collaterals are shown at the electron microscopic level in Figures 8, 9, and 11.

cosity, which might have been considered as a presynaptic bouton at the light microscopic level (Fig. $8 A$ ), was, in fact, a postsynaptic element packed with mitochondria and devoid of synaptic vesicles (Fig. $8 C, D, F$ ). One-half of the boutons that formed synapses with this axon collateral were in contact with the varicosity (Fig. $8 C, F$ ).

The other profile that appeared as a thin axon collateral in the light microscope (Fig. 9A) was found to arise from a somatic extension that gave rise to the axon hillock at the electron microscopic level (Fig. 9B). Analysis in serial sections of the proximal portion (1-5 $\mu \mathrm{m}$ from the soma) of this process revealed that it was not presynaptic but, rather, an element receiving asymmetric synaptic inputs from three boutons that were nonimmunoreactive for GABA (Fig. 9D) and displayed the ultrastructural features of the L-type terminals (Fig. 9C,D).

A second neuron with a thin collateral detaching from the main axon (not illustrated) also was examined in the electron microscope.
In line with the observations described for the first neuron (Figs. $8-9)$, this intrinsic collateral was not found to be presynaptic.

\section{Fine dendritic profiles, the so-called "axon-like processes"}

As shown in previous studies, RT neurons were found to be endowed with fine dendritic varicose processes that may resemble synaptic terminals at the light microscopic level (see Fig. 5A,a), raising the possibility that they may be presynaptic structures (Spreafico et al., 1988; Cox et al., 1996). To verify this issue, we examined such varicose processes in the electron microscope. The selected elements were located at varying distances from the perikaryon, and all had the same appearance. Such a neuron (Fig. 10) was found to have given rise to a fine dendrite dividing into two beaded branches. We did not find evidence that the corresponding varicosities were presynaptic at the electron microscopic level, but, rather, they received massive inputs from L- and D-type 

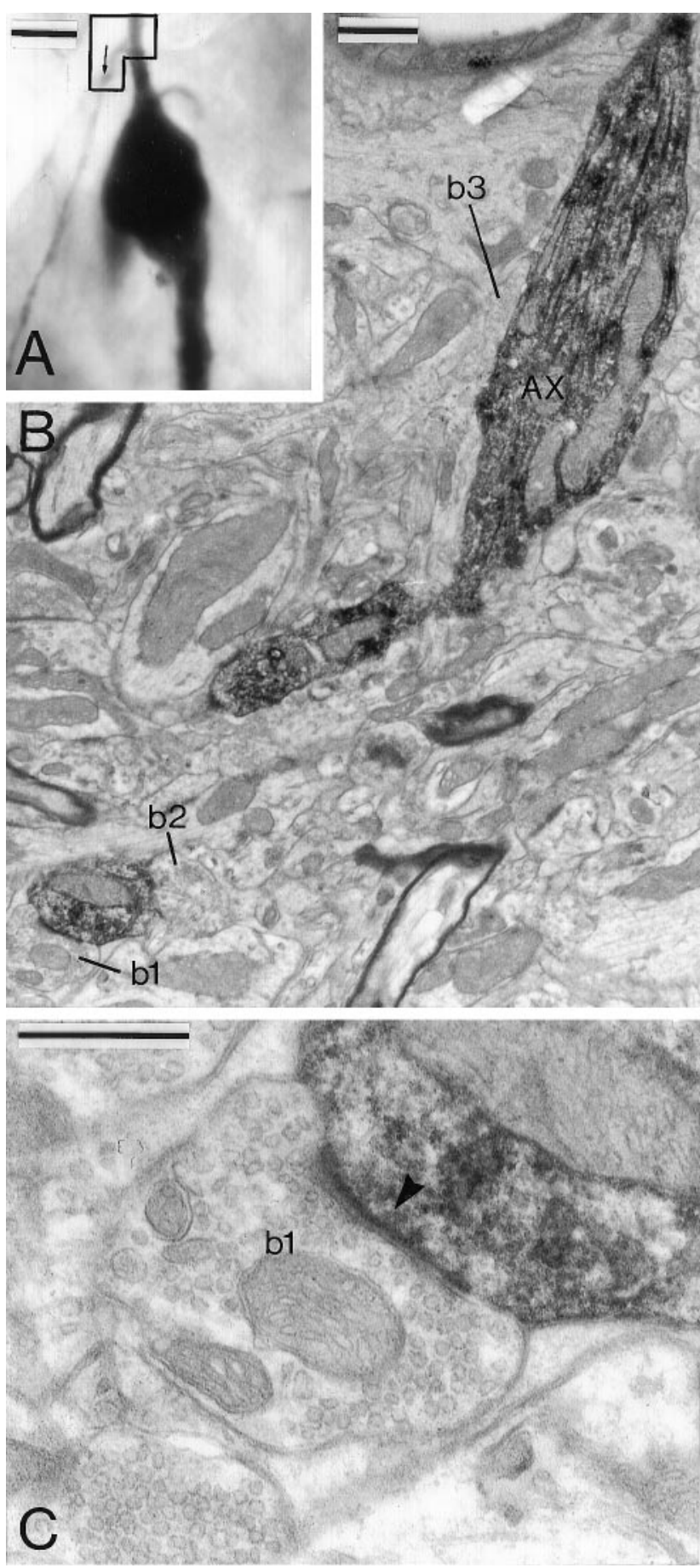
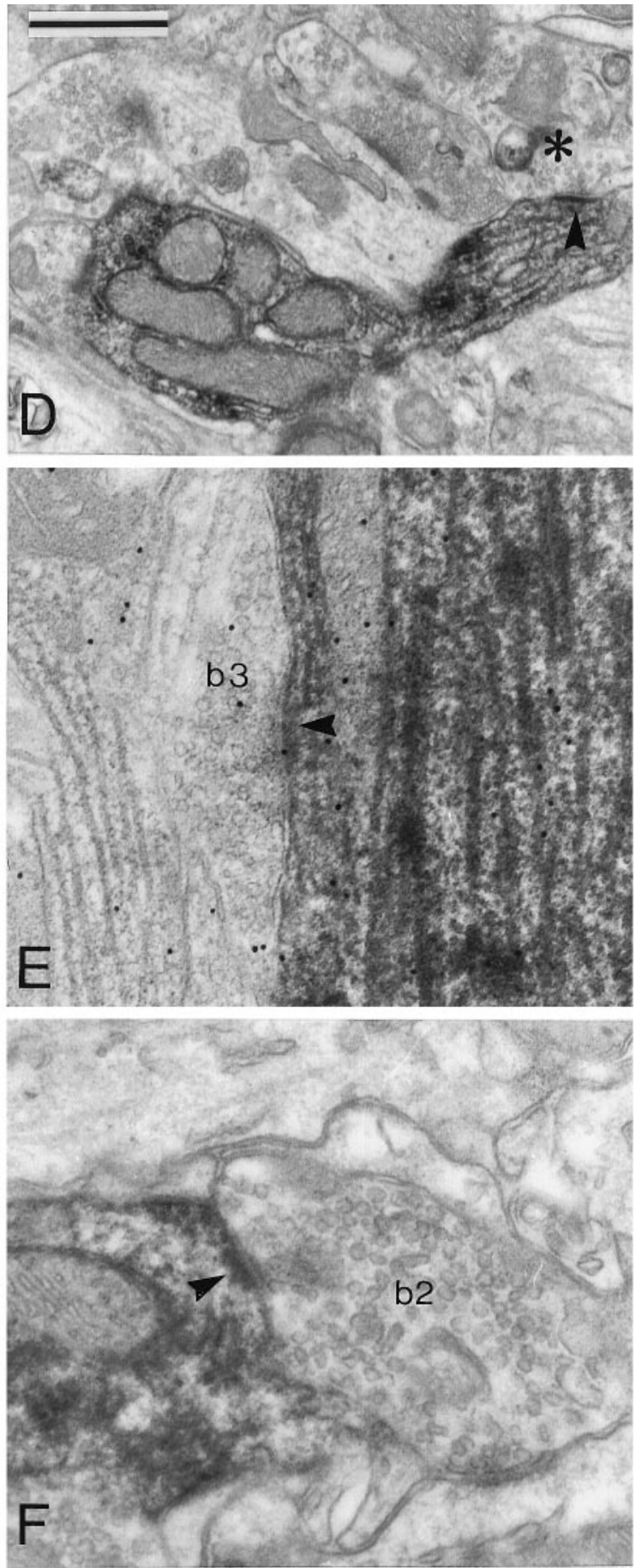

Figure 8. Correlated light $(A)$ and electron $(B-F)$ micrographs showing boutons $(b 1-b 3)$ in contact with the axon initial segment $(A x)$ and an intrinsic collateral of the RT neuron shown in Figure 7. The framed area in $A$ corresponds to that shown in $B$. The arrow in $A$ indicates the varicosity contacted by $b 1$ and $b 2$ in $B$, but the electron micrograph is rotated slightly in the clockwise direction. These two L-type terminals formed asymmetric synapses (arrowheads in $C, F$ ). The micrograph in $D$ illustrates the same varicosity in a section collected $450 \mathrm{~nm}$ deeper than that shown in $B$. Note that, at this level, the axon collateral was attached to the varicosity and formed an asymmetric synapse (arrowhead) with an unlabeled L-type bouton (asterisk). The section in $E$, which was processed for postembedding immunocytochemistry for GABA, shows a nonimmunoreactive D-type terminal (b3) that formed an asymmetric synapse (arrowhead) with the axon initial segment. Scale bars: $A, 10 \mu \mathrm{m} ; B, 1.0 \mu \mathrm{m} ; C, 0.5 \mu \mathrm{m}$ (also valid for $E, F$ ); $D, 1.0 \mu \mathrm{m}$.

boutons (Fig. 10D). Because of the dense DAB reaction product, the type of synaptic specialization associated with these boutons could not be ascertained. Similar results were obtained for all 13 fine varicose dendrites examined in the present study.

\section{Synaptic inputs on the hillock and initial segment of RT axons}

In the course of the ultrastructural analyses of the local axonal branches, we found that the hillock and initial segment of the 

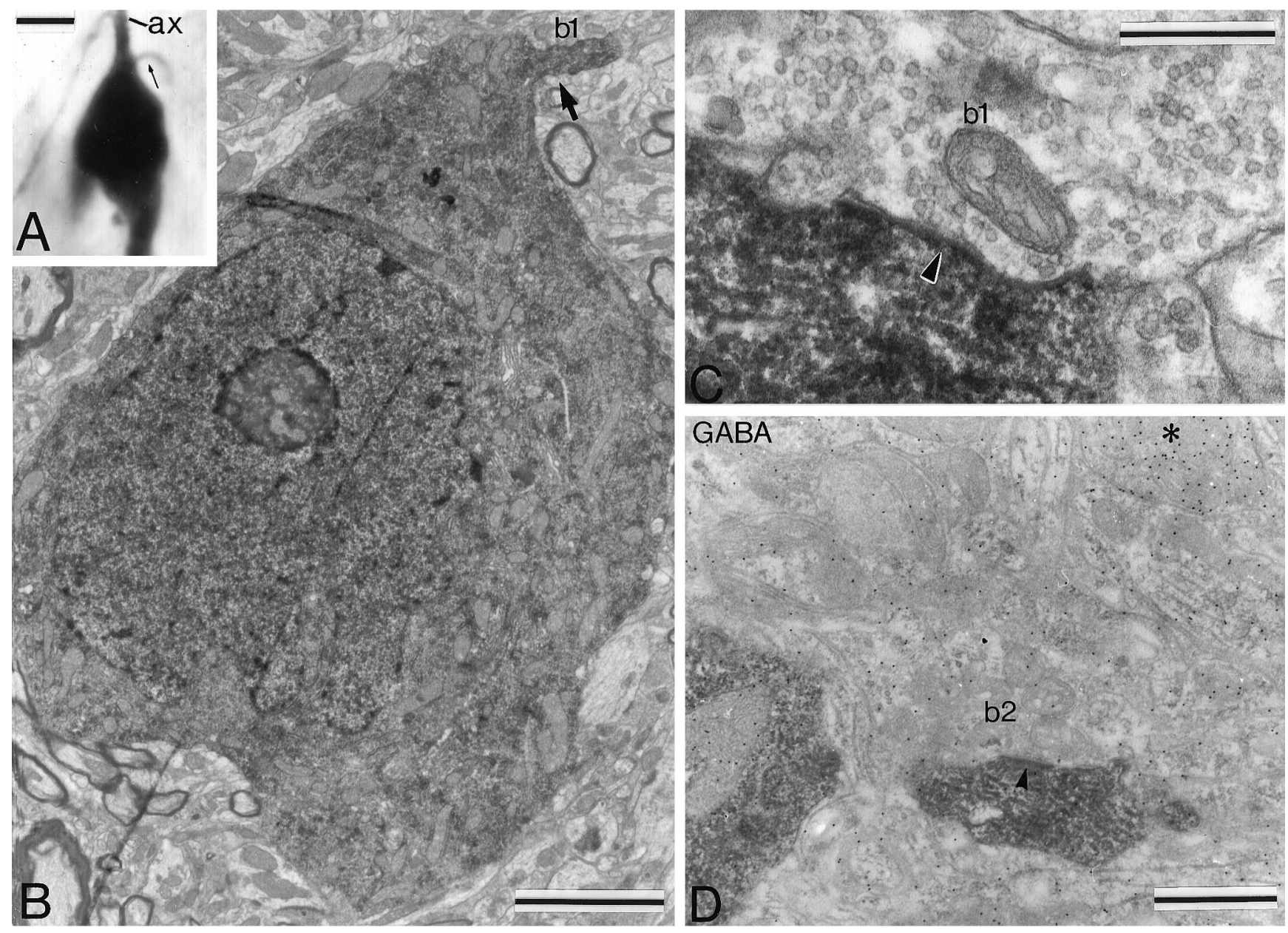

Figure 9. Correlated light $(A)$ and electron $(B-D)$ micrographs showing L-type terminals $(b 1$ and $b 2)$ that formed synapses (arrowheads in $C, D)$ with one of the intrinsic axon collaterals (arrows in $A, B$ ) of the RT neuron shown in Figure 7. $C$ is a higher power view of $b 1$. The section in $D$ was processed for the postembedding immunocytochemistry for GABA and was collected $500 \mathrm{~nm}$ deeper than $B$ and $C$. The asterisk indicates a GABA-positive dendrite. Scale bars: $A, 10 \mu \mathrm{m} ; B, 5 \mu \mathrm{m} ; C, 0.5 \mu \mathrm{m} ; D, 1.0 \mu \mathrm{m}$.

process bearing such collaterals likewise received dense synaptic innervation. Examination in serial sections revealed that the hillock received dense inputs from terminals that, for the most, formed asymmetric synapses (Fig. $11 E$ ) and were nonimmunoreactive for GABA (Fig. $11 B-D$ ). In fact, only one of the 17 boutons in contact with the hillock displayed GABA immunoreactivity $(b 3$ in Fig. $11 B, D)$. Seventy percent (12 of 17) of the boutons in contact with the hillock were of the L-type (Fig. 11C,E), whereas the remaining ( 5 of 17 ) belonged to the D-type ( $b 4$ in Fig. $11 D$ ). In the 12 cases in which the synaptic specialization could be seen, they were of the asymmetric type (Fig. $11 E$ ). The initial segment also received asymmetric synaptic inputs from GABA-negative boutons (Fig. $8 E$ ), but its density of innervation was lighter than that of the hillock and the intrinsic collaterals. Three terminals with ultrastructural features that corresponded to those of the D-type boutons (Fig. $8 E$ ) were found in contact with this part of the process.

Because of the dense DAB reaction product obscuring some of the ultrastructural features, we could not learn whether the labeled process shown in Figure 11 was an axon hillock or the proximal part of a dendrite that turned into an axon. To circumvent this problem and to ascertain the existence of axoaxonic synapses in the rat RT, we probed the synaptic innervation of the hillock and of the corresponding initial segment of four additional unlabeled RT axons (Fig. 12). These axonal processes were cut in the same plane as their parent cell body and displayed common ultrastructural features that differentiated them from dendrites: (1) they were narrower than proximal dendrites, (2) they contained microtubules that aggregated to form fascicles in a crosslink manner, and (3) they were devoid of rough endoplasmic reticulum (Fig. 12). In single ultrathin sections, the hillocks were found to receive asymmetric synaptic inputs from three to five L-type boutons (Fig. 12), whereas the initial axonal segments were much less innervated (Fig. 12). No axoaxonic synapse was found with these elements. Overall, the pattern of innervation of these unlabeled axonal structures corresponds to that described above for the proximal part of the process that bore axon collaterals (Fig. 11).

\section{Dendrodendritic synapses}

As described in previous electron microscopic studies (Scheibel and Scheibel, 1972; Ohara and Lieberman, 1985), a common feature of the RT neuropil was the formation of dendritic bundles that usually included two to five dendrites. We examined serial ultrathin sections of dendritic bundles cut along their longitudinal plane and found 18 dendrodendritic synapses and more than 30 

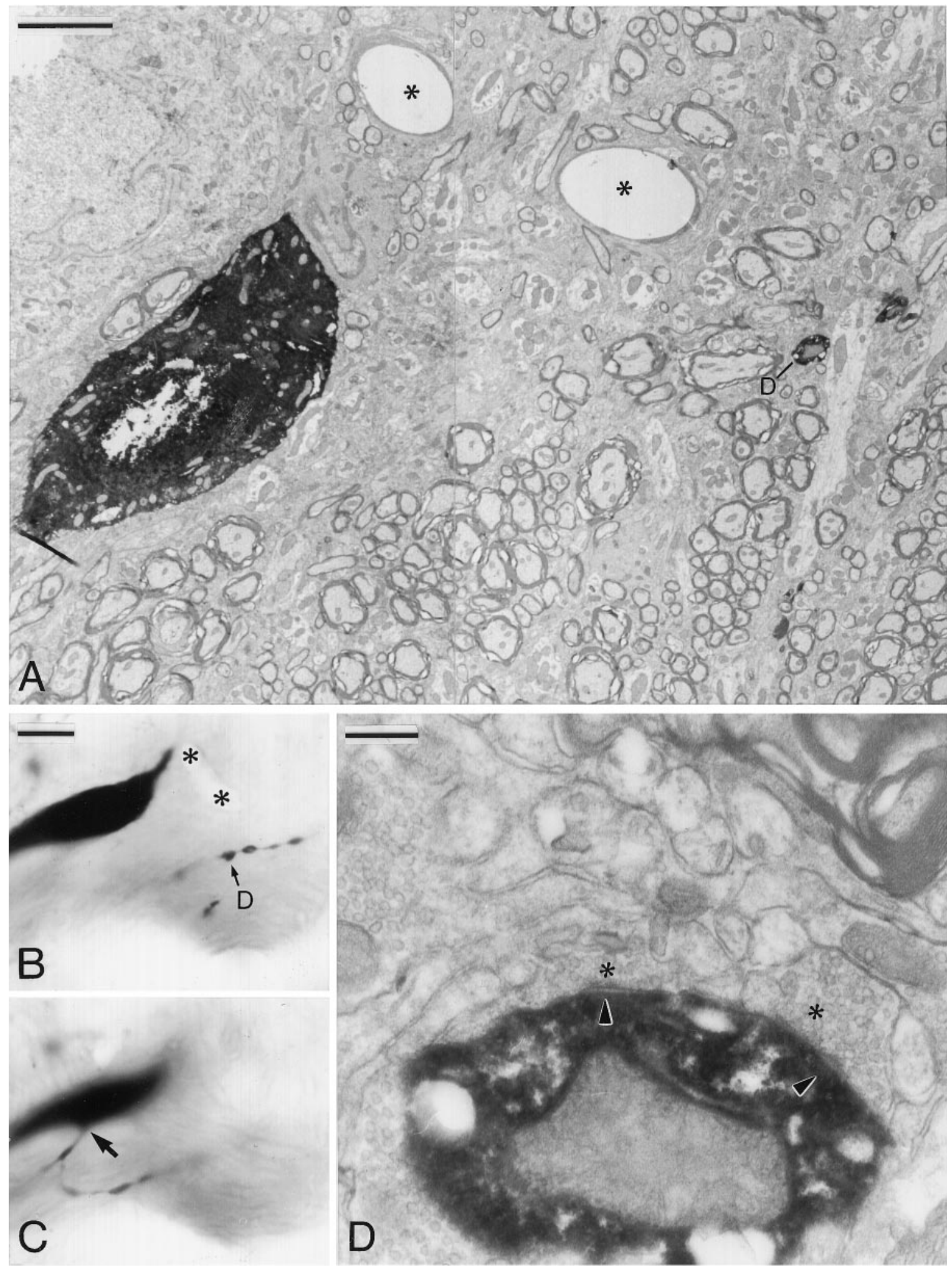

Figure 10. Correlated light $(B, C)$ and electron $(A, D)$ micrographs of a RT neuron with a fine dendrite, the so-called "axon-like processes." The perikaryon shown in $A$ corresponds to that depicted at two different focal planes in $B$ and $C$. Corresponding blood vessels in $A$ and $B$ are indicated with asterisks. Two varicosities, which arose from a thin dendritic process emerging from the perikaryon (arrow in $C$ ), are shown in $A$. One of them is shown at higher magnification in $D$. Note that it received synaptic inputs (arrowheads in $D$ ) from two unlabeled boutons (asterisks). Scale bars: $A, 5 \mu \mathrm{m} ; B, 10$ $\mu \mathrm{m}$ (also valid for $C$ ); $D, 0.5 \mu \mathrm{m}$. 

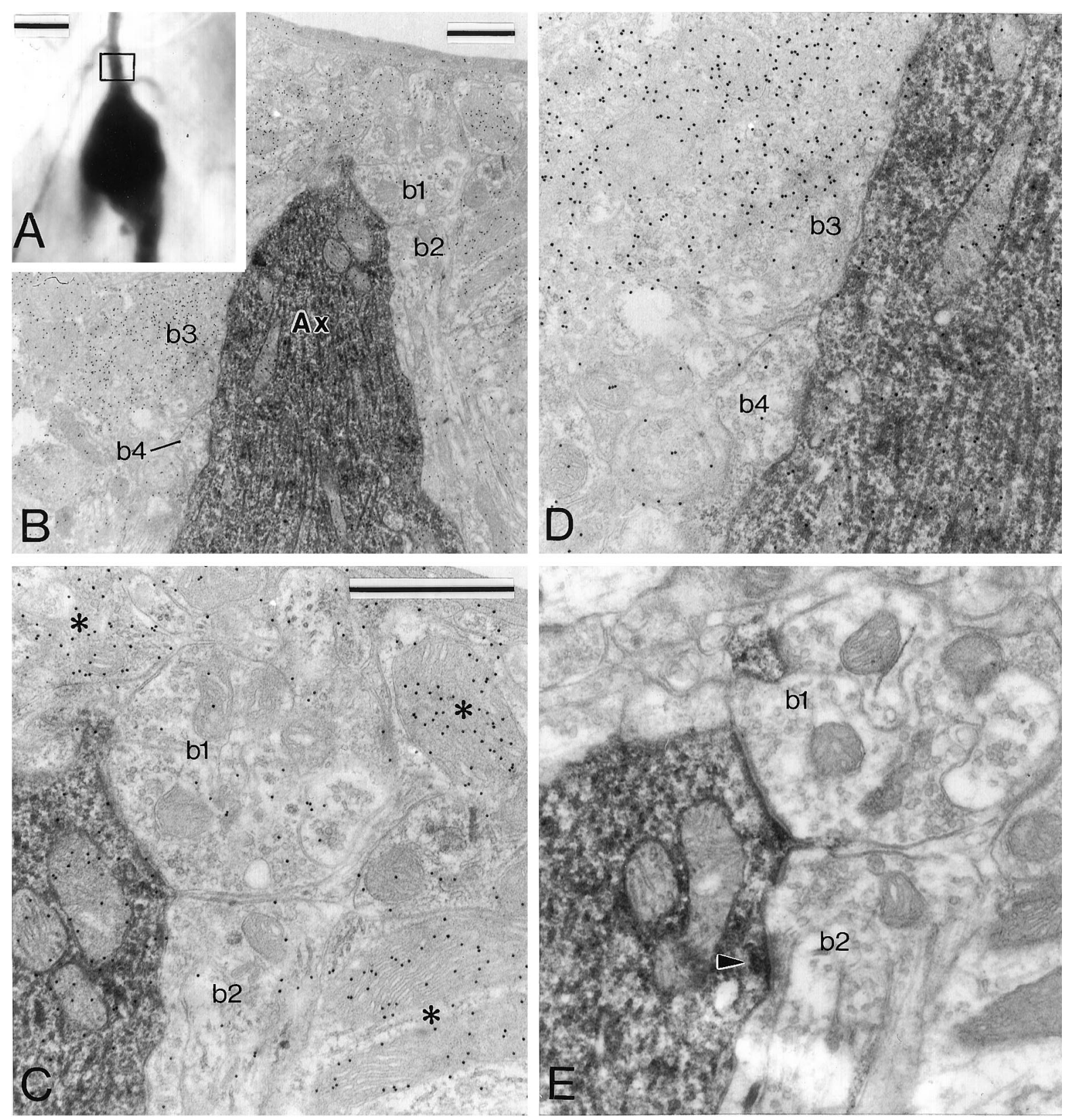

Figure 11. Correlated light $(A)$ and electron $(B-E)$ micrographs showing synaptic inputs to the presumed axon hillock $(A x)$ of the RT neuron depicted in Figure 7. Because of the dense DAB reaction product, the axonal or dendritic nature of this hillock cannot be ascertained. The framed area in $A$ is shown in $B-E$. Four boutons in contact with the axon hillock are indicated $(b 1-b 4)$ in a section that was processed for the postembedding immunocytochemistry for GABA $(B)$. The ultrastructural features of these terminals are shown at higher magnification in $C$ and $D$. One of these boutons $(b 3)$ is associated with a large density of gold particles, indicating that it displays GABA immunoreactivity. The others are nonimmunoreactive for GABA and display the ultrastructural features of L-type $(b 1, b 2)$ and D-type (b4) terminals. In $C$, the asterisks indicate GABA-containing dendrites. $E$, Shown is the asymmetric synapse associated with $b 2$ (arrowhead) in a section adjacent to $C$. Scale bars: $A, 10 \mu \mathrm{m} ; B, 1.0 \mu \mathrm{m} ; C, 1.0 \mu \mathrm{m}$ (also valid for $D, E$ ).

nonsynaptic puncta adhaerentia between the component dendrites. The dendrodendritic synapses were usually short and always of the symmetric type (Fig. 13). In addition to pleomorphic vesicles, the presynaptic dendrites (den1 in Fig. 13) contained small cisterna of endoplasmic reticulum, microtubules, and mitochondria, whereas the postsynaptic dendrites were morphologically similar except that they were devoid of synaptic vesicles. A dendrite was found to be the postsynaptic target of two dendrodendritic synapses (Fig. $13 F$ ). Contacts between two vesicle-filled structures or reciprocal synapses were not found.

\section{DISCUSSION}

The present study has unraveled several distinctive and new features of the ultrastructural organization of the RT in the adult rat. The proximal parts of the intrinsic axon collaterals that were observed in a minority of RT neurons were found to be postsynaptic structures contacted by numerous GABA-negative terminals. The so-called axon-like processes stemming from the soma or dendrites were identified as postsynaptic dendrites. Unexpectedly, the hillock and initial segment of some RT axons received 


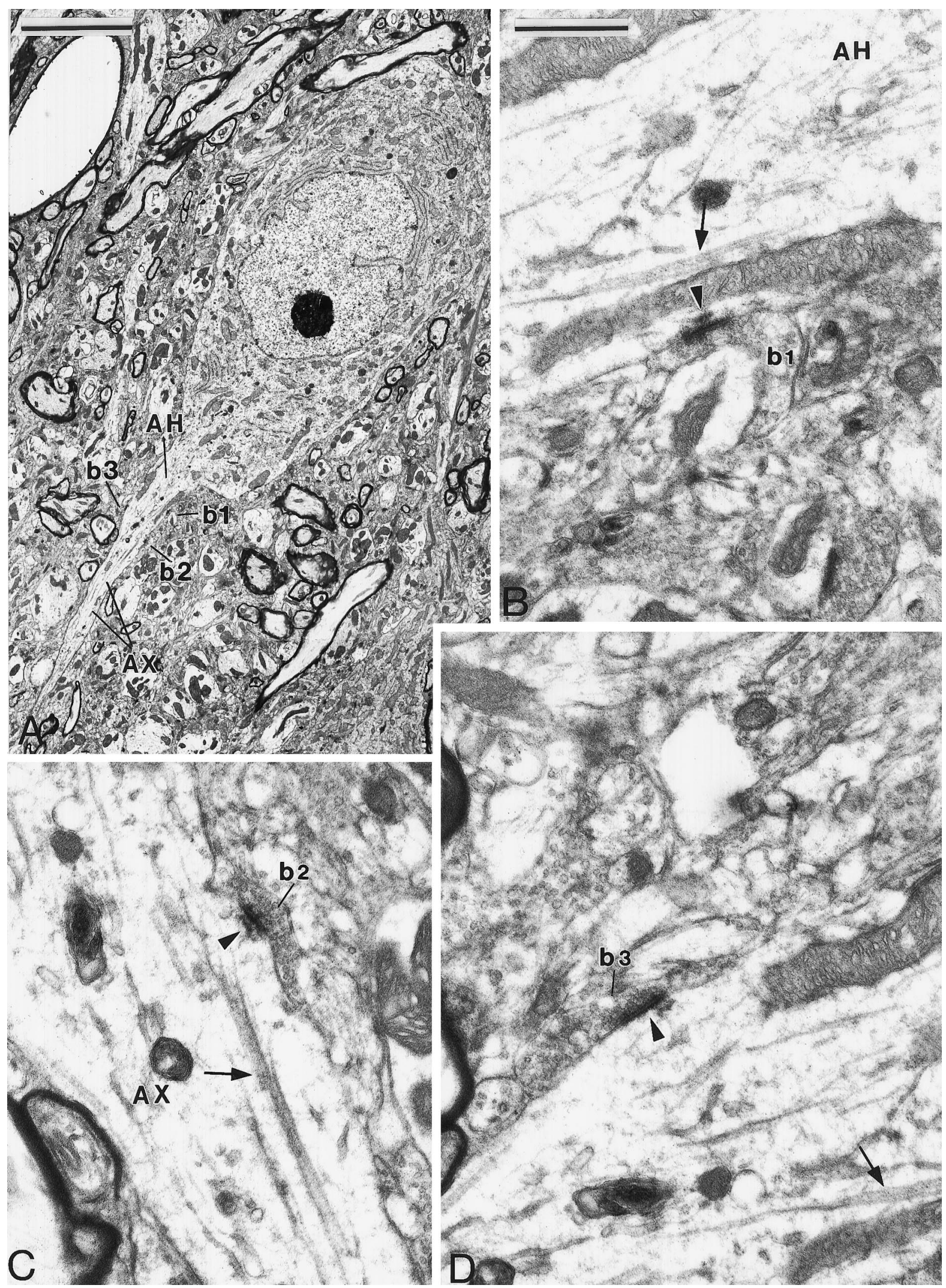

Figure 12. Synaptic inputs to the axon hillock $(A H)$ and initial axonal segment $(A X)$ of an unlabeled RT neuron. $A$, Shown is a low power view of the neuron. Three L-type terminals $(b 1-b 3)$ form asymmetric synapses with the axon. $B-D$, Shown are higher power views of these terminals. The arrowheads indicate asymmetric membrane specializations. Note that microtubules come together to form fascicles (arrows), a typical ultrastructural feature of axonal segments. Scale bars: $A, 5.0 \mu \mathrm{m} ; B, 1.0 \mu \mathrm{m}$ (also valid for $C, D$ ). 

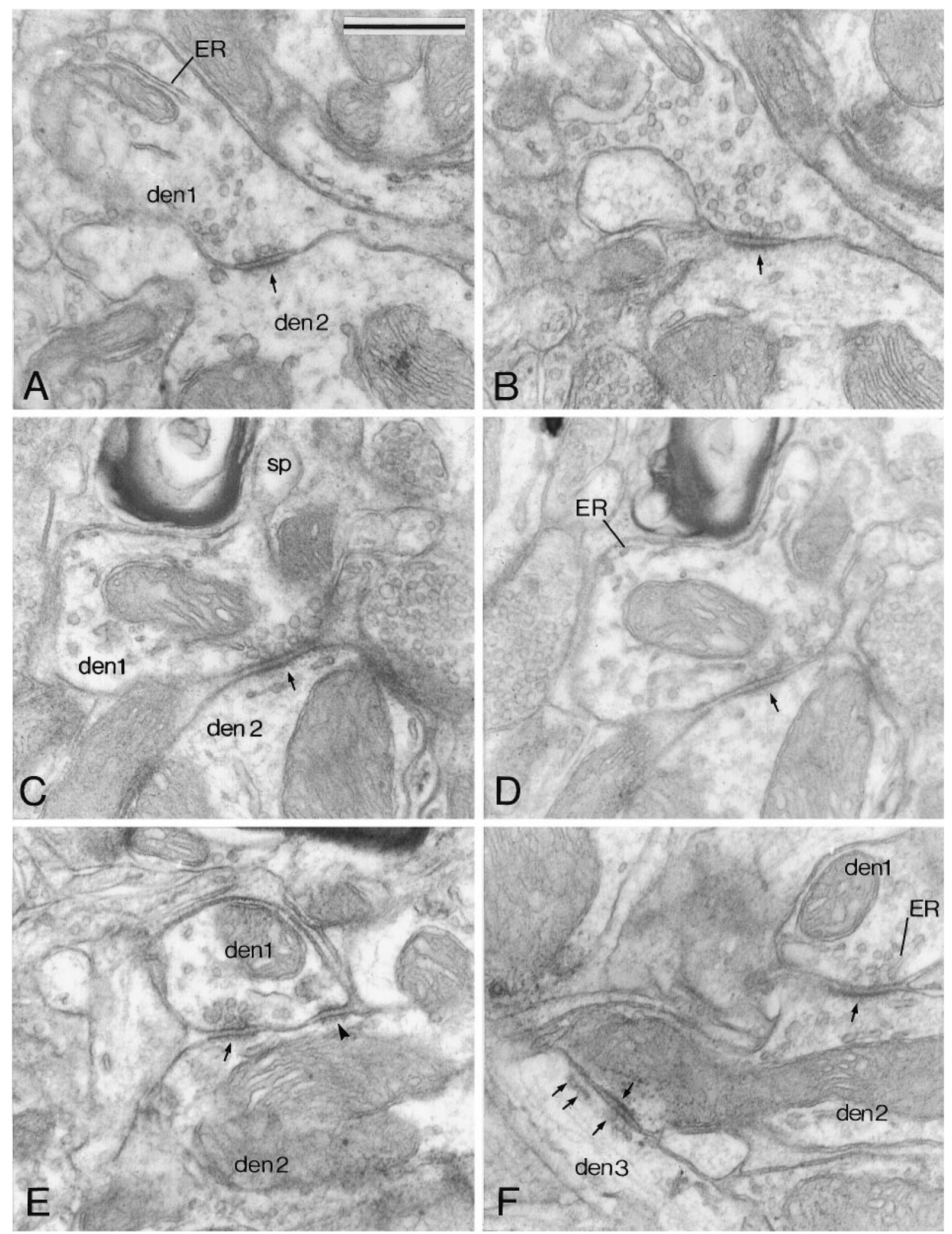

Figure 13. Examples of dendrodendritic symmetric synapses (arrows) in the RT. $A, B$ and $C$, $D$ show pairs of adjacent sections. In both cases den 1 contained pleomorphic electron-lucent vesicles and was presynaptic to den2. Stalks of smooth endoplasmic reticulum $(E R)$ are indicated in $A$ and $D$. A spine-like process $(s p)$ emerged from den 1 in $C$ and $D$. E shows two dendrites (den1 and den2) linked by both a dendrodendritic symmetric synapse (arrow) and a punctum adhaerens (arrowhead). $F$, The dendritic shaft den 2 was postsynaptic to two dendrites (den1 and den3) that contained pleomorphic vesicles aggregated at the active zone. Because the specimen was titled to show the synaptic specializations, the vesicles in den 3 (arrows) are out of focus, but they were easier to visualize in adjacent untitled sections. Stalks of smooth endoplasmic reticulum $(E R)$ are indicated in $\operatorname{den} 1$. Scale bar in $A, 0.5 \mu \mathrm{m}$ (also valid for $B-F)$. 
dense asymmetric synaptic inputs. Finally, several short symmetric dendrodendritic synapses and numerous puncta adhaerentia were observed. The functional significance of these anatomical features will now be discussed in the light of previous relevant data.

\section{Technical considerations}

Most of the data reported so far on the anatomical substrate of RT cell-cell communication were obtained by either electron microscopic analysis of unlabeled RT elements (Ohara and Lieberman, 1985; Ohara, 1988) or light microscopic examination of Golgi-stained (Scheibel and Scheibel, 1966) or tracer-filled RT neurons (Yen et al., 1985; Mulle et al., 1986; Spreafico et al., 1988; Lübke, 1993; Liu et al., 1995; Cox et al., 1996). Using the juxtacellular labeling technique, we could perform correlated light and electron microscopic analysis of single RT neurons, the axonal and dendritic arborizations of which had been characterized at first. Unlike the intracellular labeling technique, the juxtacellular method allows us to ascertain that the recorded neuron is still alive after withdrawing the pipette tip from its membrane (Pinault, 1996). This approach, therefore, increases the chance to obtain well labeled healthy neurons without significant loss of ultrastructural features. The injected neurons then can be reconstructed fully and unambiguously, and specific parts can be examined in the electron microscope. The reliability and sensitivity of the juxtacellular technique have been discussed in previous reports (Pinault, 1994, 1996). Particularly relevant for the present study is the fact that this single-cell labeling method allows for the staining of thin axonal processes, including intrinsic axon collaterals (Pinault, 1996). The trajectory of most of the tracer-filled RT axons could be followed from the perikaryon to the terminal field in the thalamus. Therefore, the high degree of sensitivity, reliability, and ease of use make the juxtacellular technique the best approach for reaching the objectives of the present study.

\section{Intrinsic postsynaptic collaterals arising from RT axons}

Currently, it is believed that RT cells in rat, cat, and monkey are endowed with local axon collaterals that presumably serve as a substrate for interneuronal communication (see introductory remarks). This idea originated from evidence based on light microscopic examination of tracer-filled RT neurons (Yen et al., 1985; Mulle et al., 1986; Spreafico et al., 1988; Uhlrich et al., 1991; Lübke, 1993; Liu et al., 1995; Cox et al., 1996). In keeping with these findings, we could identify effectively at the light microscopic level the thin processes that detached from the main axon of labeled neurons. These axon collaterals were, however, found in only $11 \%$ of injected neurons, suggesting that intrinsic axonal ramifications are probably not a prominent structural feature of RT neurons in the adult rat. On the contrary, the majority $(65 \%)$ of biocytin-filled RT cells with local collaterals was found in young animals (Cox et al., 1996), suggesting that such local processes may be lost during development. In the electron microscope we noticed that, in fact, in adult rats the proximal parts of such processes were postsynaptic to numerous GABA-negative boutons that should control the output of RT neurons. Whether or not our observations are valid in young animals and other species remains to be established. Thin postsynaptic processes emerging from the axon initial segment also were found on pyramidal neurons in the rat hippocampus (Kosaka, 1980). Because only the proximal part of identified axon collaterals has been examined in the electron microscope, we cannot rule out the possibility that the distal part of these processes may be presynaptic.

\section{Excitatory axoaxonic synapses on the hillock and initial segment of RT axons}

An interesting observation made in the course of the electron microscopic analysis was that the hillock and initial segment of some RT axons received dense synaptic inputs from GABAnegative terminals. Our findings further indicate that axoaxonic asymmetric synapses are quite frequent in the RT of adult rats. The four unlabeled axon hillocks and initial segments examined received asymmetric synapses from L-type terminals. Similarly, the hillock and initial segment of the axon of a biocytin-filled neuron received dense synaptic innervation. Although we could not ascertain definitively, because of the DAB deposit, that the hillock of the labeled neuron was that of an axon or a dendrite that turned into an axon, the pattern and density of innervation were quite similar to those of unlabeled axon hillocks. The fact that an axon hillock is the postsynaptic target of presumed excitatory terminals is quite exceptional, not only for the RT but for the entire CNS (Palay et al., 1968; Peters et al., 1991). Synapses with the axon hillock and initial segment are usually rare and mostly involve inhibitory boutons in other structures of the CNS (Jones and Powell, 1969; Kosaka, 1980; Somogyi et al., 1983; Peters et al., 1991). On the contrary, we found a single GABAcontaining terminal in contact with the axon of RT neurons. All of the other boutons displayed the ultrastructural features of L-type terminals. Previous degeneration or tract-tracing studies showed that this type of terminal arises from thalamocortical neurons (Ohara and Lieberman, 1985; Ohara, 1988). It is worth noting that synaptic inputs on the axon hillock were encountered rarely in previous ultrastructural studies of the RT in rats, cats, and monkeys (Montero and Singer, 1984; Ohara and Lieberman, 1985; Yen et al., 1985; Ohara, 1988; Williamson et al., 1994). There is no clear explanation for this discrepancy, although the fact that brains used in our study were cut in the horizontal plane and serially examined in the electron microscope probably increased the probability of finding axon hillocks and neuronal perikarya in the same ultrathin sections. A larger sampling of RT neurons with or without local axon collaterals currently is being analyzed in the electron microscope to probe the frequency and the location of those receiving dense synaptic inputs on the axon hillock. Whatever the results of these future studies are, our data provide the first evidence that the output of some RT axons is under the control of massive, presumably excitatory, afferents at the level of their hillock and initial segment.

Our findings, therefore, imply that some of the intra-RT collaterals of thalamocortical axons subserve a powerful control on the output of RT neurons. Because the axon initial segment is the privileged site for action potential initiation (Häusser et al., 1995), this region is strategically more important than the somatodendritic complex for the control of spike initiation. So, direct control of this particular region by excitatory inputs might shunt the conventional somato-dendritic integration processes. Whether or not all L-type boutons in contact with the same axon hillock and/or initial segment arise from single or many thalamocortical axons is currently under investigation in our laboratory. This is quite an important issue to clarify, because thalamic inputs on RT axons might be a powerful mechanism to generate synchronized oscillations in the thalamocortical system. Assuming that one thalamocortical neuron pinpoints the axon hillock and/or the initial segment of several RT neurons, an action potential or burst discharge in the thalamocortical cell could make numerous RT neurons fire or burst simultaneously, which, in turn, could 
inhibit a subset of thalamocortical neurons in a synchronous manner, and so on. The synchronization of bursting RT neurons during sleep spindles, for instance, therefore could be generated either by cell-cell communication in the RT and/or by thalamocortical inputs on their axon hillock and/or their initial segment.

\section{Dendrodendritic synapses and puncta adhaerentia: functional implications?}

Dendrodendritic synapses in the RT or perigeniculate nucleus were seen frequently in the cat but encountered much more rarely in the monkey (see introductory remarks). In their comprehensive study of the ultrastructure of the RT in the rat, Ohara and Lieberman (1985) found that all of the dendrites were "similar in appearance and exclusively postsynaptic." They identified only three examples of synaptic specializations between two vesiclecontaining structures, and one of them involved an element showing similarities with presynaptic dendrites (see Fig. 28 in Ohara and Lieberman, 1985). In our material we saw 18 dendrodendritic synapses and more than 30 puncta adhaerentia between dendrites in the rat RT. The presynaptic dendrites and synaptic specializations were similar in appearance to those previously shown in the cat (Ide, 1982; Deschênes et al., 1985). Various possibilities can explain the discrepancy between our findings and those of Ohara and Lieberman (1985). We followed dendritic bundles in 10-15 serial ultrathin sections to verify the existence of dendrodendritic synapses. Although some elements were examined in serial sections, there is no mention that this was the case for dendritic bundles in the study of Ohara and Lieberman (1985). This is quite an important difference, because dendrodendritic synapses are relatively short [see also Ide (1982) in the cat], which make them unlikely to be seen in single sections. Indeed, the dendrodendritic synapses that were observed in the present study could be visualized in a maximum of four serial sections; in the remaining sections the dendrites were tightly apposed, but no evidence of synapses was found. Other possibilities, including difference in the strain of rat and location of the RT area examined in the electron microscope, also should be considered.

Although dendrodendritic synapses in the thalamus have long been characterized (Famiglietti, 1970; Ralston, 1971), their functional correlate has not been demonstrated directly yet. Assuming that dendrodendritic synapses play a significant role in the RT, one may expect such junctions to generate inhibitory (see discussions by Deschênes et al., 1985; Mulle et al., 1986) or excitatory effects in RT neurons. Indeed, the polarity (hyperpolarization vs depolarization) of membrane potential changes induced by such synapses may depend on the value of the chloride equilibrium potential with respect to the actual membrane potential of the cell (Misgeld et al., 1986). Recent physiological and pharmacological works strongly suggest that local RT cell-cell communication may operate via GABAergic inhibitory synapses. (1) In adult cats and rats intracellular iontophoresis of chloride ions or local application of $\mathrm{GABA}_{\mathrm{A}}$ receptor antagonists onto RT cells induced disinhibition in in vivo preparations (Mulle et al., 1986; Pinault and Deschênes, 1992b). (2) $\mathrm{GABA}_{\mathrm{A}}$ receptor-mediated inhibitory postsynaptic potentials were recorded in RT neurons in thalamic slices of young rats, and the application of $\mathrm{GABA}_{\mathrm{A}}$ receptor antagonists increased their excitability (Huguenard and Prince, 1994; Ulrich and Huguenard, 1995, 1996). On the basis of our observations, one can believe that the anatomical substrate of such inhibitory events was dendrodendritic synapses. This hypothesis, however, remains to be verified, because dendrodendritic bundles are not well developed in young animals (Scheibel and
Scheibel, 1972; Roney et al., 1979). Another alternative explanation would be that the inhibitory postsynaptic potentials were generated by intrinsic axon collaterals that seemed to be much more frequent in young (Cox et al., 1996) than in adult rats (present study). However, further studies in young animals are needed to demonstrate whether such local processes are presynaptic structures. (3) GABAergic inhibitory postsynaptic potentials also were recorded in perigeniculate cells of the ferret in vitro during thalamic oscillations (Bal et al., 1995) or during local application of glutamate (Sànchez-Vives and McCormick, 1996). $\mathrm{GABA}_{\mathrm{A}}$ receptor-mediated inhibitory postsynaptic potentials apparently were generated by the repetitive burst discharges of neighboring perigeniculate neurons. Because dendrodendritic synapses were observed in both rats and cats, one would expect that such junctions likewise underlie the intra-RT lateral inhibitions recorded in ferrets. The functioning of these eventual synapses implies that action potentials could propagate along the dendrites of RT neurons; otherwise, the anatomical substrate underlying the results in ferrets may be intrinsic axon collaterals. Morphofunctional and pharmacological studies of simultaneously recorded presynaptic and postsynaptic RT cells thus are necessary to better characterize the mechanisms by which dendrodendritic synapses control the activity of neuronal populations in the RT. On the basis of the present results, it is tempting to suggest that the dendrodendritic synapses are ideal candidates to synchronize adjacent RT cells and that the synchronization of remote RT neurons may be underlaid by thalamocortical axoaxonic synapses.

In keeping with previous data (Ohara and Lieberman, 1985), nonsynaptic punctum adhaerens-like junctions commonly were found between dendrites in the RT. Whether or not such specializations are potential sites for nonsynaptic electrical and/or nonelectrical interneuronal communications remains to be established (for review, see Roney et al., 1979).

\section{Axon emerging from a dendrite: functional consequences?}

More than $50 \%$ of tracer-filled RT cells analyzed in our study had their axon emerging from a proximal dendrite, which sometimes already had given rise to dendritic ramifications. In very few cases, the axon originated from a distal dendrite, and, exceptionally, some neurons had two axons emanating from distinct locations. These structural features bring up an important issue concerning the location of the final site of synaptic integration in RT neurons. They also introduce complication for interpreting the nature of spike-like small potentials that sometimes were observed in RT cells (Contreras et al., 1993). Assuming that action potentials are generated on the axon initial segment (Häusser et al., 1995), they could propagate forward along the axon and backward along the axon-bearing dendrite, acting as an anterograde and retrograde signal, respectively. Thereby, back-propagating action potentials could interfere with the receptive and integrative properties of the somatodendritic complex (Markram et al., 1995; Pinault, 1995). They may, for instance, provide a powerful stimulus to activate dendrodendritic synapses. Moreover, presumed dendritic spikes were recorded in some RT neurons in vivo and in vitro (Llinás and Geijo-Barrientos, 1988; Contreras et al., 1993). Such spikes could trigger plateau potentials and subsequent action potentials further (Contreras et al., 1993).

We have observed that the axonal trunk of some RT neurons had a dendrite-like appearance because it bore swellings not only in the RT but also in the thalamus (see Fig. 4), so we could not determine the exact origin of the axon on these neurons; unfor- 
tunately, no such cell subsequently could be examined in the electron microscope. Whether or not these axonal swellings were presynaptic or postsynaptic structures thus remains an open question. The light microscopic observations also raise the question as to whether such "dendrite-like" axons are myelinated. More studies, thus, are needed to better characterize these proximal axonal structures and, eventually, to know whether RT cells having such a thick varicose axon have a particular function. In addition, one may wonder whether or not such axonal swellings, supposing they did not result from a subsequent axonal reaction to tracer filling, represent a normal developmental morphological differentiation (e.g., age-related process) or the early manifestation of a pathological process (Jellinger, 1973).

\section{REFERENCES}

Adams JC (1981) Heavy metal intensification of DAB-based HRP reaction product. J Histochem Cytochem 29:775.

Bal T, von Krosigk M, McCormick DA (1995) Role of the ferret perigeniculate nucleus in the generation of synchronized oscillations in vitro. J Physiol (Lond) 483:665-685.

Canadian Council on Animal Care (1993) Guide to the care and use of experimental animals (Olfert ED, Cross BM, McWilliam AA, eds). Ottawa: Bradda.

Contreras D, Curró Dossi R, Steriade M (1993) Electrophysiological properties of cat reticular thalamic neurones in vivo. J Physiol (Lond) 470:273-294.

Cox C, Huguenard JR, Prince DA (1996) Heterogeneous axonal arborizations of rat thalamic reticular neurons in the ventrobasal nucleus. J Comp Neurol 366:416-430.

Dale N, Ottersen OP, Roberts A, Storm-Mathisen J (1986) Inhibitory neurones of a motor pattern generator in Xenopus revealed by antibodies to glycine. Nature 324:255-257.

Deschênes M, Madariaga A, Steriade M (1985) Dendrodendritic synapses in the cat reticularis thalami nucleus: a structural basis of thalamic spindle synchronization. Brain Res 334:165-168.

Famiglietti Jr EV (1970) Dendro-dendritic synapses in the lateral geniculate nucleus of the cat. Brain Res 20:181-191.

Häusser M, Stuart G, Racca C, Sakmann B (1995) Axonal initiation and active dendritic propagation of action potentials in substantia nigra neurons. Neuron 15:637-647.

Hodgson AJ, Penke B, Erdei A, Chubb IW, Somogyi P (1985) Antisera to gamma-aminobutyric acid. I. Production and characterization using a new model system. J Histochem Cytochem 33:229-239.

Houser CR, Vaughn JE, Barber RP, Roberts E (1980) GABA neurons are the major cell type of the nucleus reticularis thalami. Brain Res 200:341-354.

Huguenard JR, Prince DA (1992) A novel T-type current underlies prolonged $\mathrm{Ca}^{2+}$-dependent burst firing in GABAergic neurons of rat thalamic reticular nucleus. J Neurosci 12:3804-3817.

Huguenard JR, Prince DA (1994) Clonazepam suppresses $\mathrm{GABA}_{\mathrm{B}}$ mediated inhibition in thalamic relay neurons through effects in nucleus reticularis. J Neurophysiol 71:2576-2581.

Ide LS (1982) The fine structure of the perigeniculate nucleus in the cat. J Comp Neurol 210:317-334.

Jellinger K (1973) Neuroaxonal dystrophy: its natural history and related disorders. Prog Neuropathol 2:129-180.

Jones EG, Powell TPS (1969) Synapses on the axon hillocks and initial segments of pyramidal cell axons in the cerebral cortex. J Cell Sci 5:495-507.

Kosaka T (1980) The axon initial segment as a synaptic site: ultrastructure and synaptology of the initial segment of the pyramidal cell in the rat hippocampus (CA3 region). J Neurocytol 9:861-882.

Liu XB, Warren RA, Jones EG (1995) Synaptic distribution of afferents from reticular nucleus in ventroposterior nucleus of cat thalamus. J Comp Neurol 352:187-202.

Llinás RR, Geijo-Barrientos E (1988) In vitro studies of mammalian thalamic and reticularis thalami neurons. In: Cellular thalamic mechanisms (Bentivoglio M, Spreafico R, eds), pp 23-33. Amsterdam: Excerpta Medica.

Lübke J (1993) Morphology of neurons in the thalamic reticular nucleus (TRN) of mammals as revealed by intracellular injections into fixed brain slices. J Comp Neurol 329:458-471.
Markram H, Helm PJ, Sakmann B (1995) Dendritic calcium transients evoked by single back-propagating action potentials in rat neocortical pyramidal neurons. J Physiol (Lond) 485:1-20.

Misgeld U, Deisz RA, Dodt HU, Lux HD (1986) The role of chloride transport in postsynaptic inhibition of hippocampal neurons. Science 232:1413-1415.

Montero VM, Singer W (1984) Ultrastructure and synaptic relations of neural elements containing glutamic acid decarboxylase (GAD) in the perigeniculate nucleus of the cat. A light and electron microscopic immunocytochemical study. Exp Brain Res 56:115-125.

Mulle C, Madariaga A, Deschênes M (1986) Morphology and electrophysiological properties of reticularis thalami neurons in cat: in vivo study of a thalamic pacemaker. J Neurosci 6:2134-2145.

Ohara PT (1988) Synaptic organization of the thalamic reticular nucleus. J Electron Microsc Technol 10:283-292.

Ohara PT, Lieberman AR (1985) The thalamic reticular nucleus of the adult rat: experimental anatomical studies. J Neurocytol 14:365-411.

Palay SL, Sotelo C, Peters A, Orkand PM (1968) The axon hillock and the initial segment. J Cell Biol 38:193-201.

Paxinos G, Watson C (1986) The rat brain in stereotaxic coordinates. Sydney: Academic.

Peters A, Palay SL, Webster HdeF (1991) Synapses. In: The fine structure of the nervous system: neurons and their supporting cells, pp 192-195. New York: Oxford UP.

Phend KD, Weinberg RJ, Rustioni A (1992) Techniques to optimize postembedding single and double staining of amino acid neurotransmitters. J Histochem Cytochem 40:1011-1020.

Pinault D (1994) Golgi-like labeling of a single neuron recorded extracellularly. Neurosci Lett 170:255-260.

Pinault D (1995) Backpropagation of action potentials generated at ectopic axonal loci: hypothesis that axon terminals integrate local environmental signals. Brain Res Rev 21:42-92.

Pinault D (1996) A novel single-cell staining procedure performed in vivo under electrophysiological control: morpho-functional features of juxtacellularly labeled thalamic cells and other central neurons with biocytin or Neurobiotin. J Neurosci Methods 65:113-136.

Pinault D, Deschênes M (1992a) Voltage-dependent $40 \mathrm{~Hz}$ oscillations in rat reticular thalamic neurons in vivo. Neuroscience 51:245-258.

Pinault D, Deschênes M (1992b) Control of $40 \mathrm{~Hz}$ firing of reticular thalamic cells by neurotransmitters. Neuroscience 51:259-268.

Pinault D, Bourassa J, Deschênes M (1995a) The axonal arborization of single thalamic reticular neurons in the somatosensory thalamus of the rat. Eur J Neurosci 7:31-40.

Pinault D, Bourassa J, Deschênes M (1995b) Thalamic reticular input to the rat visual thalamus: a single fiber study using biocytin as an anterograde tracer. Brain Res 670:147-152.

Pinault D, Smith Y, Deschênes M (1996) Combined light and electron microscopic evidence for the lack of intrinsic axon collaterals and the existence of dendro-dendritic synapses in the thalamic reticular nucleus of the rat. Soc Neurosci Abstr 22:2030.

Ralston III HJ (1971) Evidence for presynaptic dendrites and a proposal for their mechanism of action. Nature 230:585-587.

Reynolds ES (1963) The use of lead citrate as high $\mathrm{pH}$ as an electron opaque stain in electron microscopy. J Cell Biol 17:208-212.

Roney KJ, Scheibel AB, Shaw GL (1979) Dendritic bundles: survey of anatomical experiments and physiological theories. Brain Res Rev 1:225-271.

Sànchez-Vives MV, McCormick DA (1996) Lateral inhibition in the perigeniculate nucleus of the ferret. Soc Neurosci Abstr 22:1447.

Scheibel ME, Scheibel AB (1966) The organization of the nucleus reticularis thalami: a Golgi study. Brain Res 1:43-62.

Scheibel ME, Scheibel AB (1972) Specialized organizational patterns within the nucleus reticularis thalami of the cat. Exp Neurol 34:316-322.

Society for Neuroscience (1991) Handbook for the use of animals in neuroscience research. Washington, DC: Society for Neuroscience.

Somogyi P, Hodgson AJ (1985) Antisera to gamma-aminobutyric acid. III. Demonstration of GABA in Golgi-impregnated neurons and in conventional electron microscopic sections of cat striate cortex. J Histochem Cytochem 33:249-257.

Somogyi P, Nunzi MG, Gorio A, Smith AD (1983) A new type of specific interneuron in the monkey hippocampus forming synapses exclusively with the axon initial segments of pyramidal cells. Brain Res 259:137-142.

Somogyi P, Hodgson AJ, Chubb IW, Penke B, Erdei A (1985) Antisera 
to gamma-aminobutyric acid. II. Immunocytochemical application to the central nervous system. J Histochem Cytochem 33:240-248.

Spreafico R, De Curtis M, Frassoni C, Avanzini G (1988) Electrophysiological characteristics of morphologically identified reticular thalamic neurons from rat slices. Neuroscience 27:629-638.

Steriade M, Parent A, Hada J (1984) Thalamic projections of nucleus reticularis thalami of cat: a study using retrograde transport of horseradish peroxidase and fluorescent tracers. J Comp Neurol 229:531-547.

Steriade M, Jones EG, Llinás RR (1990) Thalamic oscillations and signaling. New York: Wiley.

Thomson AM (1988) Inhibitory postsynaptic potentials evoked in thalamic neurons by stimulation of the reticularis nucleus evoke slow spikes in isolated rat brain slices-I. Neuroscience 25:491-502.

Uhlrich DJ, Cucchiaro JB, Humphrey AL, Sherman SM (1991) Mor- phology and axonal projection patterns of individual neurons in the cat perigeniculate nucleus. J Neurophysiol 65:1528-1541.

Ulrich D, Huguenard JR (1995) Purinergic inhibition of GABA and glutamate release in the thalamus: implications for thalamic network activity. Neuron 15:909-918.

Ulrich D, Huguenard JR (1996) GABA $_{\mathrm{B}}$ receptor-mediated responses in GABAergic projection neurones of rat nucleus reticularis thalami in vitro. J Physiol (Lond) 493:845-854.

Williamson AM, Ohara PT, Ralston DD, Milroy AM, Ralston III HJ (1994) Analysis of gamma-aminobutyric acidergic synaptic contacts in the thalamic reticular nucleus of the monkey. J Comp Neurol 349:182-192.

Yen CT, Conley M, Hendry SHC, Jones EG (1985) The morphology of physiologically identified GABAergic neurons in the somatic part of the thalamic reticular nucleus in the cat. J Neurosci 5:2254-2268. 